This is a Pre-Print version of the following article:

Luca Chiapperino and Francesco Panese, 'On the Traces of the Biosocial: Historicizing "Plasticity" in Contemporary Epigenetics', History of Science, 18 November 2019, 42, https://doi.org/10.1177/0073275319876839.

1 On the traces of the biosocial: historicizing plasticity in contemporary

2 epigenetics

\title{
3 Introduction
}

4 In current epigenetics, the notion of biological 'plasticity' ${ }^{11}$ plays a pivotal role. The interplay among the genome, the epigenome and the environment is deemed capable of providing explanations for the aetiology of most common diseases and life-course health trajectories. ${ }^{2}$ Plasticity thinking helps to legitimate normative evaluations of the alleged responsibilities of individuals and collectives (including governments) to protect the epigenomes of present and future generations. ${ }^{3}$ Modifications and adaptations of the body mediated by environmental stimuli, social conditions, and life-course experiences extend molecular understandings of both healthy and diseased phenotypes to encompass epigenetic effects potentially passed to future generations. ${ }^{4}$ The biographies and biologies of multiple generations seem to be linked by means of malleable and stable epigenetic marks, ${ }^{5}$ which revive the centrality of plasticity in evolutionary thinking under the heading of epigenetically acquired characters. ${ }^{6}$ Plasticity is, in other words, an operational concept that both inspires a series of cognate - yet distinct - research programs in epigenetic sciences and calls for a re-negotiation of the traditional boundaries between the social and biological understandings of (human) life. By dissecting the plastic adaptations of our biology to its material and social environments, contemporary epigenetics broadens the horizon of the life sciences to a potentially biosocial epistemology ${ }^{7}$ that challenges the irreducible oppositions between social and biological understandings of life.

In this paper, we build upon historico-epistemological analyses of plasticity across the $19^{\text {th }}$ and $20^{\text {th }}$ centuries in order to distinguish among uses of this notion in contemporary epigenetics. By digging into this diachronic phase of plasticity thinking, we highlight a series of historicallysituated understandings and pragmatic dimensions of this notion. These different versions of plasticity allow us, in turn, to discern synchronically how plasticity in epigenetics encompasses distinct visions and experimental practices that make sense of the reciprocal entanglement of (human) bodies and their (material and social) environments. Parallel to this analysis of the "epistemic spaces ${ }^{8}$ of plasticity from the $19^{\text {th }}$ century onward, we show how these distinct modes of understanding body-environment relationships also constituted conceptual, representational, and experimental resources for understanding the entanglement between life as biological and socially situated phenomenon. These different traces of the biosocial ante litteram, we conclude, 
This is a Pre-Print version of the following article:

Luca Chiapperino and Francesco Panese, 'On the Traces of the Biosocial: Historicizing "Plasticity" in Contemporary Epigenetics', History of Science, 18 November 2019, 42, https://doi.org/10.1177/0073275319876839.

1 may be at play also in contemporary epigenetics and post-genomics and thus constitute an entry

2 point onto the assumptions, values, (social) ontologies and political leanings populating

3 contemporary life sciences.

4 As to the diachronic dimension, we reconstruct the role of plasticity thinking in the longue durée of

5 debates about phenotypic development and evolution in modern biology (i.e. from the $19^{\text {th }}$

6 century onwards). Plasticity thinking, we argue, structured and directed epistemic practices

7 towards distinct understandings of how human biology acts in concert with environmental

8 influences. Specifically, our analysis describes four distinct phases in plasticity thinking across the

$9 \quad 19^{\text {th }}$ and $20^{\text {th }}$ centuries: (i) plasticity as chemical modification of the body by its milieu; (ii) plasticity as explanandum for the modifications of life's ontogenetic and phylogenetic substrates; (iii) plasticity as mechanistic process in need of distinct explanations in ontogeny and phylogeny; and (iv) plasticity as responsive potential to perturbations of a complex genetic system of development. These different conceptions of plasticity, we argue, reveal distinct interpretations of how the material substrate of our biology is permeable and susceptible to its environments. This element, as we shall see, also offers the opportunity to show how plasticity was an epistemic resource to interpret, demarcate and govern the boundaries between biological and social aspects of (human) life, and consequently allows us to describe different traces of the biosocial in its historical and epistemological trajectory.

With regard to the synchronic dimension, we show how these four ways of interpreting and operationalizing plasticity can be used to characterize and distinguish present uses of this notion in epigenetic biosciences. In this respect, our work differs from a history of why and how plasticity thinking re-emerged in recent biology. ${ }^{9}$ Rather, our paper aligns with the current wave in history, philosophy and social studies of science which interprets and criticizes contemporary biology by situating it in a longer history ${ }^{10}$. To do so, we draw several parallels between past characterizations of plasticity and its uses in epigenomics, behavioral epigenetics, environmental epigenetics and molecular epidemiology. Our work highlights how epigenetic views of the plastic body are a far more complex, historically tangled and idiosyncratic construction than it is generally believed. ${ }^{11}$ While some authors have argued that epigenetics constitutes a novel discovery of the body's permeability, memory and porosity, ${ }^{12}$ our analysis counters this belief on historical grounds and provides a typology of plasticities as long-standing heuristics of bodyenvironment relationships that currently co-exist in epigenetics. In this respect, our paper may be read as an illustration of how the vital traffic bodies-milieux in contemporary life sciences is 
This is a Pre-Print version of the following article:

Luca Chiapperino and Francesco Panese, 'On the Traces of the Biosocial: Historicizing "Plasticity" in Contemporary Epigenetics', History of Science, 18 November 2019, 42, https://doi.org/10.1177/0073275319876839.

1 actually a panoply of distinct epistemic programs and, potentially, biosocial strategies for

2 governing and making sense of this plastic nexus.

3 Certainly, our focus on the similarities across temporally distant mobilizations of plasticity is 4 inescapably defective as to the sharp contrasts between the styles of reasoning ${ }^{13}$ in contemporary

5 molecular biology and pre-genetic biological thinking. Yet, we argue, our work can be useful both

6 (i) to illuminate some of the preconditions that make thinking the idea of plasticity possible

7 today, ${ }^{14}$ and (ii) to perform "a historical dissolution of self-evident identities"15 among cognate

8 practices of knowledge-making in contemporary biology. As to the former, our paper calls for a critical approach to the alleged 'revolution' ascribed to epigenetics in its societal circulation. ${ }^{16}$ Our historical and epistemological analysis of plasticity capitalizes on "the interpretative purport of [historians'] achievements" ${ }^{\prime 17}$ in order to question epigenetics' allegedly novel openings towards a biology of body's permeability, memory and porosity. Contrary to this view, we show that these concepts have been a constant matter of discussion and uncertainty (at least) since the onset of biological thinking as an organized domain of knowledge ${ }^{18}$. As to the latter, the identification of various theorizations (and operationalizations) of body-environment relations in contemporary epigenetics shows the diverse explanatory functions plasticity affords in the epistemic landscape of post-genomics. Thanks to the comparisons we draw with historically-situated interpretations of plasticity, our paper offers a counter-point to the prevailing assumption that the origin of the different scientific programs in epigenetics can be found in the ideas of Conrad Hal Waddington - the widely recognized founder of 'epigenetics'. ${ }^{19}$ In contrast to this view, the historical cases we present allow us to describe how distinct epistemologies of plasticity co-exist alongside Waddington-inspired research programs in current epigenetics. Fleshing out these historical ramifications animating the present, we argue, reveals a fundamental epistemological disagreement at the basis of the controversies around the definition of the scope and epistemic priorities of epigenetics: how to reconcile the contemporary epistemologies of plasticity that hold epigenetic marks capable to bear the material impression of the environment with those grounded on a strong view of (epigenetic) plasticity as operating under genetic control?

Finally, our work offers also the opportunity to recast in a longer history the biosocial openings ascribed to contemporary epigenetics. ${ }^{20}$ Plasticity thinking, in the diachronic trajectory we investigate, did not simply constitute the epistemic construction of an understanding of the reciprocal modulation of organic substrates and their (material and social) environments in 
This is a Pre-Print version of the following article:

Luca Chiapperino and Francesco Panese, 'On the Traces of the Biosocial: Historicizing "Plasticity" in Contemporary Epigenetics', History of Science, 18 November 2019, 42, https://doi.org/10.1177/0073275319876839.

1 embed the body's biology within coeval socio-political contexts. Plasticity provided in fact a

2 repertoire of mechanisms and explanations that could account for a fundamental hybridity

3 between our biological and social existence - with the resulting consequence that it also

4 constituted the basis to inspire political action. These traces of the biosocial avant la lettre, we

5 conclude, raise the question as to how similar concerns may be raised by contemporary debates

6 in and around epigenetics.

7 Part 1 - The diachronic dimension: 'plasticity' across the $19^{\text {th }}$ and $20^{\text {th }}$ centuries

8 The idea of plasticity has a very long history ${ }^{21}$ extending back to 'environmental theories' of

9 health and inheritance of acquired characters in Hippocrates. ${ }^{22}$ It is already found, for example, in

10 Plato, who attempts to account for the memory and the mind as substances molded by perception and thought. ${ }^{23}$ Furthermore, as we learn from philosopher Catherine Malabou, ${ }^{24}$ the idea of plasticity in Aristotle designates a twofold process of receiving and giving form, which is exemplified by the phenomenon of perception as both passivity of the senses (i.e. the inscription of an alterity in the sensible substratum) and realization of the potential of the perceptive faculty itself (i.e. sensing as the achievement of the natural function to sense the external world).

Between these two poles of passive molding/imprinting and active autodetermination/actualization of potentiality lies the semantic space of plasticity which we will investigate in the remainder of the paper. Yet, from the Greek adjective $\pi \lambda \alpha \sigma \tau \omega x$ os (plastikos) to cognate notions such as 'plasma' in $19^{\text {th }}$ century theories of heredity and contemporary mobilizations of plasticity in epigenetics, what we can observe is less the supposedly very old stabilization of one concept than the historically-situated attempts to answer a cardinal question: how to account for the reciprocal modulation of organic substrates and their (material and social) environments? Answering this question has, in other words, taken a far from linear route that is specific to times ${ }^{25}$ and places $^{26}$ of scientific as well as humanistic ${ }^{27}$ interrogation, and whose reconstruction goes beyond the scope of the present analysis. However, it is worth underlining here why focusing on the diachronic dynamics of plasticity thinking across the $19^{\text {th }}$ and $20^{\text {th }}$ centuries is pivotal to a critical uptake of this notion in contemporary epigenetics.

First, the $19^{\text {th }}$ century marks the stabilization of questions related to plasticity as matters of methodical observation. In an attempt to render the dominant Hippocratic-Galenic views in medicine less dogmatic, $18^{\text {th }}$ century European medical schools shifted towards theoretical refinement and accumulated evidence, which fostered more sophisticated explanations of disease, adaptation and their inheritance. At the dawn of the $19^{\text {th }}$ century, the emergence of disease and its 
This is a Pre-Print version of the following article:

Luca Chiapperino and Francesco Panese, 'On the Traces of the Biosocial: Historicizing "Plasticity" in Contemporary Epigenetics', History of Science, 18 November 2019, 42, https://doi.org/10.1177/0073275319876839.

1 transmission through generations comes to be approached in terms of plausible physiological

2 causal routes and through the accumulation of case histories, which replace the traditional

3 explanations grounded on familial, group or local causes. ${ }^{28}$ As argued by Müller-Wille and

$4 \quad$ Brand $^{29}$ the $19^{\text {th }}$ century marks the progressive assemblage of an epistemic space of

5 representational, conceptual and practical tools in biological thinking, which gradually turned into

6 the consolidation of the 'epistemic objects' of the dedicated discipline of genetics with its defined

7 spaces, concepts, standards and technologies. Following the diachronia of plasticity in this period

8 is thus a way to restrict our analysis to the moments in which the long history of plasticity

9 thinking ${ }^{30}$ bifurcated into a construction and product of an (increasingly) organized episteme.

10 Second, the interest in plasticity thinking across the $19^{\text {th }}$ century (and beyond) can also be explained by the social and political conditions that stand in a dynamic of co-production with the episteme of that time. The $19^{\text {th }}$ century approaches to plasticity we analyze are in fact coeval to the emergence of the preoccupation on the side of institutions and the state to make populations healthier. In this respect, a focus on this historical period enables a description of how plasticity thinking has been recruited to solidify "mechanisms, techniques and technologies of power" over the body of a population. ${ }^{31}$ More specifically, the $19^{\text {th }}$ century offers the possibility of observing not only one period in which the body is cast as an entity open and permeable to its surroundings. Rather, $19^{\text {th }}$ century cases shed also light on the explicit epistemic construction of the body as a socially determined phenomenon to be governed by means of intervention on the social and material milieu. As we will see later, conceptions of the plastic body across the $19^{\text {th }}$ century (and beyond) mark the debut of institutional, administrative and political actions directed at intervening ${ }^{32}$ on the effects of social and material environments for ontogeny and - later in the century of heredity ${ }^{33}$ - phylogeny. In other words, the $19^{\text {th }}$ century offers the opportunity to historicize plasticity as a way to give shape to biosocial understandings of the human condition, which have implications for the biopolitical governing of the body qua biological and social entity.

Restricting our focus to the $19^{\text {th }}$ and $20^{\text {th }}$ centuries certainly overlooks the continuities and analogies that run throughout the history of plasticity from Hippocrates to theories of pathological heredity and degeneration. ${ }^{34}$ Furthermore, the selection of cases we present here is meant only to extrapolate key themes in the last two centuries of plasticity thinking and not to provide a comprehensive analysis of the complex developments related to this notion across this same period. ${ }^{35}$ Yet, we have selected these cases because they enable us to unpack major 
This is a Pre-Print version of the following article:

Luca Chiapperino and Francesco Panese, 'On the Traces of the Biosocial: Historicizing "Plasticity" in Contemporary Epigenetics', History of Science, 18 November 2019, 42, https://doi.org/10.1177/0073275319876839.

1 epistemological differences among alternative strands of contemporary epigenetic research. Our case studies are particularly useful in that they highlight distinct epistemo-political avenues of plasticity thinking, which mark the distinctions among some of the most relevant approaches in current epigenetics. By subjecting the body-environment porosity to methodical investigation, by setting up factual elements for political reforms and the functioning of nascent institutions, and by theorizing the need to address plasticity as a social problem for present and future generations, the theorizations of plasticity over the $19^{\text {th }}$ and $20^{\text {th }}$ centuries we analyze offer a privileged entry point on the $21^{\text {st }}$ versions of these very same concerns in epigenetic biosciences.

\subsection{French public bygiene: a paradigm of chemical alteration of the body}

By the end of the $18^{\text {th }}$ century, the problematization of the human body as an entity modified by its environments takes an important epistemo-political turn in several national contexts. ${ }^{36}$ Here, we focus on the case of France, whose cultural tradition was dominated by a mechanistic conception of biology, which postulated a materialist and deterministic understanding of the body, its environments and their relationship. ${ }^{37}$ Within this context, the notion of 'milieu' played a pivotal role to theorize processes of evolutionary transformations in their well-known Lamarckian formulation: "les animaux doivent leur forme générale aux influences du milieu dans lequel ils babitent ${ }^{\prime 38}$ Yet, it is by means of the coeval ${ }^{39}$ hygienist movement that systematic theories aimed explicitly at understanding "the influence of physical things on man" became concrete elements for political strategies to promote "the means of preserving health." These two quotes are in fact the subtitle of the founding treaty "Elements of Hygiene" (1802) by Etienne Tourtelle (1756-1801). Three elements are particularly interesting in the case of French hygienists. First, the human body is conceived as a metabolic chemical entity - before the term metabolism was coined ${ }^{41}$ - whose state is 'modified' by its exposure to external factors, such as the 'atmosphere:'

\footnotetext{
The human body, in the midst of the atmosphere, does not have to be thought merely as a mass upon which atmospheric influences act physically, but also as a blend within which chemicals bonds are established between its principles and those of the air. At last, as organized body [...], the buman body receives particular modifications from the atmosphere. ${ }^{42}$
}

Second, the hygienist movement formulates and renders operational a taxonomy of chemical alterations of the body promised to a long fortune. Through the identification of discrete "matters of hygiene" whose chemical action on the body renders them "health modifiers,"43 hygienists isolate distinct patterns of body-milieu interaction on which to act in order to preserve health: 
This is a Pre-Print version of the following article:

Luca Chiapperino and Francesco Panese, 'On the Traces of the Biosocial: Historicizing "Plasticity" in Contemporary Epigenetics', History of Science, 18 November 2019, 42, https://doi.org/10.1177/0073275319876839.

Circumfusa: the action that bodies exert upon us, like the atmosphere, the places, water, climate.

Applicata: the things that are applied to the surface of our bodies, such as clothes, baths, frictions, cosmetics, etc.

Ingesta: the ingested substances, such as food and drinks.

Excreta: all that relates to excretions.

Gesta: physical exercise and any voluntary action.

Percepta: the influence that our perceptions exert upon the animal economy by means of the encephalon and our nervous system. ${ }^{44}$

Inspired by the nascent chemical episteme of Antoine-Laurent de Lavoisier (1743-1794), ${ }^{45}$ French hygienism constitutes a strong research program devoted to the establishment of an environmental and social aetiology of disease. In this program, diseases are described as mechanical and chemical phenomena emerging at the intersection of external actions and internal effects. The methodical collection of statistics about the living and working conditions of Parisian workers, as well as the recollection of systematic observations about the effects of their milieux on health constitute a theorization of the importance of discerning healthy and unhealthy bodily states as the product of material and social determinants of pathogenic alterations. Needless to say, this view of disease aetiology also has a bearing upon the conceptions of sanitary therapy developed by hygienists.

In fact, a third element worth noting in operationalizations of plasticity thinking in the hygienist movement relates to their approach to the management of these health modifiers. Their taxonomy of chemical alterations of the body gradually crystallizes in a political-moral duty to protect individuals by acting on the milieu; less so to restore the health of individuals than to preserve them from external threats. Besides the fact that therapeutics were poorly developed in this period, several concurring factors contributed to the focus of hygienists on actions addressed at the reducing the pathogenicity of living conditions. Primarily, medical approaches of the time in France as well as in other contexts ${ }^{46}$ - largely privileged the attendance to the manifestations rather than the causes of disease on the states of mind and the body. Going under the label of "expectant medicine," ${ }^{, 47}$ this approach to the treatment of diseases consisted in the recognition of the 'natural' tendency of the body towards cure. Thus, the treating role of the physician consisted more in accompanying the body's intrinsic vital actions to restore health (e.g. through the elimination of external threats), rather than in the administration of artificial remedies to eliminate morbid states. Secondly, before the advent of the Third Republic produced a new political elite with a large component of doctors, the first actors and theoreticians of hygiene in France were liberal chemists who tended to oppose the interference of the state in private affairs such as individual health and treatments. For these reasons, hygienists implemented what 
This is a Pre-Print version of the following article:

Luca Chiapperino and Francesco Panese, 'On the Traces of the Biosocial: Historicizing "Plasticity" in Contemporary Epigenetics', History of Science, 18 November 2019, 42, https://doi.org/10.1177/0073275319876839.

1 philosopher Gérard Jorland has called a "socio-clinical" 48 approach to the protection of

2 populations from the threats of their environments. Similarly to what characterized the

3 emergence of public health in other national contexts, ${ }^{49}$ French hygienists did not focus on the

4 treatment of disease, but rather implemented 'treatment' strategies for the population that

5 consisted in the systematic removal of all potential factors of morbidity from the living

6 conditions, habits and material urban environments of citizens. For instance, the nutrition of

7 workers constituted the object of medical interventions directed at improving its quality, its

8 cleanliness, its distribution and its nutritional value all for the purpose of preventing the

9 development of diseases in this population:

Human beings are surrounded by dangers; their frail existence is incessantly threatened by thousands of destructive plagues; its organization subject to the trial of alterations that expose them to a multitude of aches at every moment. ${ }^{50}$

Thus, at the beginning of $19^{\text {th }}$ century we observe that the hygienist movement provided an elaborate conception of the reciprocal modulations of bodies and their environments that is grounded in mechanistic explanations formulated in the grammar of nascent modern chemistry. This operationalization of a plastic conception of the body instructed, in turn, institutionalized practices of sanitation, which constituted a historical precedent of health promotion interventions taking place at the crossroad of the organic interiority of the body and the socio-material configurations of its environments. Thus, the permeability of the body to its milieu is, for $19^{\text {th }}$ century hygienists, not only a theorization of the chemical relationship between the organic interiority of the former and the chemical activity of the latter. Rather, it constitutes also the fundamental ground for institutional, administrative and political actions directed at governing such bio-social nexus.

\subsection{Metaphorical conjectures about 'organic memory'}

The question of heredity became a central issue of biological theories in the middle of the $19^{\text {th }}$ century. ${ }^{51}$ Besides the confrontations between Lamarckism and Darwinism, this epoch witnessed a density and proliferation of positions, arguments and experimental practices, which resulted in numerous conceptions of heredity. Such debates straddled the biological and social conceptions of the term, and constituted a prolific epistemic space in which "taxonomies, [...] arguments, $[\ldots]$ architectures of hereditary knowledge, and the conjunctions of these elements" started to circulate in a variety of social arenas. ${ }^{52}$ In order to navigate such space, the monumental work of the French zoologist Yves Delage (1854-1920) constitutes a remarkable milestone. In "La structure 
This is a Pre-Print version of the following article:

Luca Chiapperino and Francesco Panese, 'On the Traces of the Biosocial: Historicizing "Plasticity" in Contemporary Epigenetics', History of Science, 18 November 2019, 42, https://doi.org/10.1177/0073275319876839.

1 du protoplasme et les théories de l'bérédite ${ }^{\Re 3}$ he proposes a useful inventory of the urgent questions on

2 development, adaptation and heredity still open at that time:

If the acquired characters are transmissible, how can the modifications produced in the body be transmitted, with such admirable precision, to the germ-cells, which do not yet contain any of the organs which will be affected by them? If they are not [transmissible], how can the progress of the adaptation of beings to their environment be made?54

At a time in which the structures and the functions of these processes remained largely unobservable at the microbiological level, Delage - and many others - tried to answer these fundamental questions essentially in two complementary ways: first, by looking for observational or experimental evidence of the transmissibility of acquired characters; second, by trying to develop general theories of heredity. One effect of this activity was the emergence of new notions accounting for the dynamics of reproduction and variation as well as stability and adaptation. Interestingly, several of these lay in a lexical space whose two coordinates are the notions of plasma (which shares the same etymology of 'plasticity') and genesis (i.e. generation, birth, descent) as illustrated in Delage's Tableau du classement des théories générales (Figure 1).

[Insert Figure 1 around here]

The epistemic space inhabited by notions such as 'protoplasm,' 'idioplasm,' 'plastidule,' 'pangenesis,' 'perigenesis' constitutes in Delage's work a specific category of physicochemical and micromerist theories, which postulate the existence of essential particles making up the basic elements of any living being. Each of these theories forms in its own way the hypothesis of the existence of "particles $[\ldots]$ of the same nature, extending [...] their influence equally to the determination of all characters." ${ }^{25}$ Today, one can read these theories as metaphorical accounts of phenomena which largely escaped direct empirical observations. These different notions may in fact be regarded as non-literal descriptions producing a coherent understanding of two intertwining processes: on the one hand, the transmission of stable characters; on the other hand, the effects of experiences on "organs, physiological functions, psychological aptitudes, instincts, etc." ${ }^{56}$ Yet, this great variety of theories is better understood as resulting from the "deeply troubled"57 status of notions of heredity, development, variation and stability in the life sciences of that time. Among the numerous attempts at solving these long-standing problems, those aiming to account jointly for several of these aspects are particularly interesting for the analyst of contemporary epigenetics. This is significantly the case of Ernst Haeckel (1834-1919). 
This is a Pre-Print version of the following article:

Luca Chiapperino and Francesco Panese, 'On the Traces of the Biosocial: Historicizing "Plasticity" in Contemporary Epigenetics', History of Science, 18 November 2019, 42, https://doi.org/10.1177/0073275319876839.

1 In order to account for the physicochemical articulation between acquisition, memory and

2 transmission, Haeckel coined the term 'Plastiden' from the abovementioned Greek plastos

3 (molded, formed). The Plastiden designated single-cell organisms, creatures of the lowest

4 morphological or physiological order of "individual." Haeckel imagined these Plastiden to be

5 filled with a substance he called 'Plasson' which in turn was composed of molecules called

6 'Plastidules,' a contraction between 'Plastid' and 'Molecule' that, he argued, 'must be considered

7 as the molecular factors of the biogenetic process. ${ }^{\prime 58}$ It is not surprising that this ontological

8 invention has been interpreted as an anticipation of DNA. ${ }^{59}$ Yet, it is important to nuance this

9 rapid and teleological interpretation. Haeckel's originality lies less in having imagined a physicochemical substrate of the phenomenon of transmission of characters - many others did that, as Delage testifies - than having tried to integrate into his theory the contextual modifications (or molding) of the very material substrate of life. Haeckel called this process the "perigenesis of plastidules." A detailed explaination of its workings can be found in the legend of his fascinating scheme (Figure 2).

[Insert Figure 2 around here]

According to Haeckel, the adaptation of plastidules to external influences and the transmission of the transformations induced by these influences can be explained by the same "plastic activity." The plastidules were understood mechanically as being subjected to "a ramified undulating movement, which propagates itself without interruption and that can be considered as the efficient cause of the biogenetic process. ${ }^{961}$ Notably, the temporalities of this process do not belong alternatively here to heredity, or contextual (phenotypic) adaptations. The modifications of the plastidular movement make it possible to account both for phenomena of contextual adaptation (i.e. modifications of the plastidular movement acquired during the life-course, which are potentially transmitted to future generations) and heredity (i.e. the accurate reproduction of the plastidular movement from one generation to another). Indeed, this unified biogenetic process is the core of his theory of organic memory: "heredity is the memory of plastidules;" variability is instead "the receptiveness" (i.e. the mnemonic capacity) of the plastidules. "The former produces stability, the latter variation of organised forms." ${ }^{\prime 62}$

Yet, Haeckel's theory also goes further in that it complements this view with a second hypothesis aimed at explaining another fundamental unity in the phenomenon of (human) life. The undulating movement of plastidules is not just a common explanation for ontogenetic and phylogenetic processes but also a heuristic for the continuity between the organic and the 
This is a Pre-Print version of the following article:

Luca Chiapperino and Francesco Panese, 'On the Traces of the Biosocial: Historicizing

"Plasticity" in Contemporary Epigenetics', History of Science, 18 November 2019, 42, https://doi.org/10.1177/0073275319876839.

1 inorganic, the biological and the psychological. ${ }^{63}$ While at a molecular level the biogenetic process

2 is characterized by the attraction and repulsion of the atoms composing it, at the level of psychic

3 faculties this very same movement manifests itself as "ordinary acts of human intelligence"

4 (we would say) sociality. Haeckel's theory affirms, in other words, a monist understanding of the

5 biological and the psychosocial aspects of life, which postulates an additive and progressive

6 continuity (both at the ontogenetic and phylogenetic level) between the basic functioning of life and those of a society. On the one hand, Haeckel affirms that instincts and social attitudes can be explained as manifestations of a faculty progressively accumulated through adaptation, and transmitted through heredity across species: "animal instincts are no more an exclusive property of animal brain than reason it is a special privilege of humans." ${ }^{65}$ On the other hand, his theory postulates a fundamental ontological unity of phenomena alternatively characterized, in present terms, as social or biological. Indeed, he argues, much as our social existence recapitulates the principles organizing our biology, the cells in our bodies can also be regarded as members of an organized society - a "cellular republic" 06 - which is affected and shaped "by education, by exercise, by habits." ${ }^{67}$ It is also "the history of human civilization," he concludes, that "explains the history of the organization of multicellular organisms." ${ }^{98}$

Haeckel's theory of organic memory provides two conceptual elements that respectively mark a departure from the hygienist paradigm in the diachronia of plasticity thinking, and highlight another way of problematizing the entanglement of biological and social dimensions of (human) life. On the one hand, his ideas account for the articulation between contextual adaptations, their memorization in the atomic structures of plastidules, and their intergenerational transmission. The theory of the 'perigenesis of plastidules' constitutes a different way of conceiving and operationalizing plasticity in that it provides a complementarist view of generation and transmission, variation and stability, adaptation and heredity. Taken at face value, ${ }^{69}$ Haeckel's theory is capable of reconciling the alleged oppositions between Lamarckian and Darwinian theories of evolution. ${ }^{70}$ On the other hand, Haeckel's theory affirms also a fundamentally monist view of the psychological, social and biological aspects of (human) life. This bio-psycho-social hybridity is made possible through the recognition of a common ontology - i.e. the undulating movement of the plastidules - governing life as both a state of conscience, individual experience or social condition and organic process of memorization and reproduction of forms in ontogeny and phylogeny. One inevitable consequence of Haeckel's theory of organic memory is thus that the monism he defended was not merely a biological thesis rooted in expert culture, but rather constituted the ground for broader social, political and lay culture endeavors. For instance, his 
This is a Pre-Print version of the following article:

Luca Chiapperino and Francesco Panese, 'On the Traces of the Biosocial: Historicizing "Plasticity" in Contemporary Epigenetics', History of Science, 18 November 2019, 42, https://doi.org/10.1177/0073275319876839.

1 drawings of developmental processes exerted a significant influence that goes beyond the field of 2 embryology throughout the $20^{\text {th }}$ century. Haeckel's artistic inclinations inspired views - and

3 attracted several criticisms - regarding the notions of history, evolution and progress they

4 entailed. $^{71}$ At a political level, both reactionary and progressive thinker justified in fact distinct

5 options of social engineering on the basis of his representations of ontogeny and phylogeny,

6 which focused respectively on the degenerative effects of social conditions and the social

7 environment as domain of intervention for regeneration. ${ }^{72}$

1.3 The experimental decoupling of ontogenetic and phylogenetic plasticity

Towards the end of the $19^{\text {th }}$ century, Haeckel's articulation of the relationships among adaptation, memory and heredity is fundamentally challenged. The decisive factor in establishing a divide between plasticity in adaptation and heredity later became known as 'Weismannism,' or - as the author himself calls it - the 'doctrine of the continuity of the germ-plasm.' In commencing his second essay ${ }^{73}$ aimed at a foundational work for a theory of heredity, August Weismann (18341914) affirms that:

When we see that, in the higher organisms, the smallest structural details, and the most minute peculiarities of bodily and mental disposition, are transmitted from one generation to another [...] we very naturally ask for the causes of such a striking phenomenon $[\ldots]$. And the immediate answer to such a question must be given in the following terms: A single cell out of the millions of diversely differentiated cells which compose the body, becomes specialized as a sexual cell; it is thrown off from the organism and is capable of reproducing all the peculiarities of the parent body in the new individual $[\ldots] \cdot]^{74}$

The doctrine rests upon the idea that heredity entails the transfer of a cell (i.e. the germ-cell), which divides early on during development from those constituting the body (i.e. the soma) and that possesses the capacity to develop into a full-blown organism after reproduction. His doctrine was grounded on the conviction that somatic differentiation entailed a progressive loss in the contents of the nuclei (i.e. the germ-plasm - another notion sharing the same etymology of plasticity). This progressive loss of determinants favored the specialization of a given cell (i.e. the expression of cellular specificities) in a given tissue. Consequently, as the complexity of the germplasm "gradually diminish[es] during ontogeny," the doctrine had to entail an early segregation of the germ-line from the somatic track. ${ }^{75}$ This was in fact the only way to preserve the full span of determinants from one generation to the other.

The separation between the germ and the soma was, however, in direct contradiction with those theories (among which figure prominently Haeckel's perigenesis and Darwin's pangenesis) holding the possibility of some inheritance of acquired characters via the progressive accumulation of somatic modifications transmitted to reproductive cells. ${ }^{76}$ Weismann had 
This is a Pre-Print version of the following article:

Luca Chiapperino and Francesco Panese, 'On the Traces of the Biosocial: Historicizing

"Plasticity" in Contemporary Epigenetics', History of Science, 18 November 2019, 42, https://doi.org/10.1177/0073275319876839.

1 therefore the problem of reconciling continuity and variation with the proposed segregation of

2 the germ line from the soma. He tried to solve it by, first, making a distinction between germ cells

3 (i.e. sperm and oocytes in sexually reproducing species) and germ plasm (i.e. the material content

4 of germ cells from which an individual develops). This way, he could combine the ideas that the

5 continuity across generations lies in the "substance of the germ-cells, or germ-plasm," and not in

6 the immutability of germ cells, "for the germ-cells are contained in the organism, and the external

7 influences which affect them are intimately connected with the state of the organism." 77 Second,

8 in a later stage of his work he admitted variations taking place in the germ-plasm itself $^{78}$ by means

9 of external influences upon the development of the germ line and through recombination during

10 fertilization. He was in fact aware of the fact that gametogenesis entailed the loss of part of determinants - what we would call today the transition from a diploid to a haploid genome. ${ }^{79}$

Weismann's work was very influential in exposing some foundational limitations of theories linking phenotypic and evolutionary plasticity such as Lamarckism. In order to craft his own theory of heredity, he dedicated a considerable effort to discussing, experimenting with and demonstrating the weaknesses of the available evidence for the transmission of acquired characters. However, his critique was directed at those cases of mutilations or wounds occurring during the lifetime of a parent supposedly transmitted to the progeny, such as the influential experiments conducted on guinea pigs by Charles-Édouard Brown-Sequard. ${ }^{80}$ These cases were problematic to him in that they entailed a modification passing from the somatic to the germ line; that is, they were in open contradiction with his experiments corroborating the early developmental segregation of the latter from the former. So, even though he excluded the "erroneous [...] hypothesis which assumes that somatic nucleoplasm may be transformed into germ-plasm," $"{ }^{81}$ nothing prevented him from holding the idea that modifications could occur in the germ-line track. In fact, as mentioned above, he also made clear in later writing ${ }^{82}$ that germ cells - in their own distinct development - may be subjected to modifications from the surrounding environment, which could produce modifications of the elements of the germ-plasm going down the phylogenetic lineage.

The appearance of Weismann's doctrine marks therefore a further moment in the recent history of plasticity thinking, which consists of a substantive distinction on experimental grounds between ontogeny and phylogeny. After Weismann, variation and stability in the germ-line require being studied in their own distinguished biological trajectory from ontogenetic processes. Weismann's ideas on the continuity of the germ-line were thus much less conclusive than they 
This is a Pre-Print version of the following article:

Luca Chiapperino and Francesco Panese, 'On the Traces of the Biosocial: Historicizing "Plasticity" in Contemporary Epigenetics', History of Science, 18 November 2019, 42, https://doi.org/10.1177/0073275319876839.

1 are usually portrayed by the familiar version that constituted 'Weismannism' throughout the $20^{\text {th }}$

2 century. ${ }^{83}$ His idea of an early separation between the soma and the germ was less monolithic

3 than it appears in later readings of his work. Weismann himself, in other words, "was not a

4 Weismannian." 84 The idea he found in need of experimental support within "the animal

5 kingdom" $" 85$ was the one according to which the progressive losses of determinants from the

6 nucleoplasm (i.e. the content of the nucleus) of somatic cells (which was conditional to cellular

7 specification in his view) could account for the complete restoration of the germ-plasm in the

8 germ cells. Contrary to what later became "a dogmatic faith in Weismannism" ${ }^{86}$ his target was the

9 missing mechanistic and experimental explanation that the smallest molecules of heredity can be

10 modified by external influences on somatic cells.

11 Weismann's doctrine is a case worth investigating also for the purpose of our inquiry into the ways plasticity thinking produced specific views of the entanglement between the biological and the social aspects of (human) life. As argued by Meloni, ${ }^{87}$ Weismann's work entails a radical shift in the study of the interactions between experiences, social conditions and the organic functioning of the body. After Weismann, it becomes possible to claim heredity as a biological phenomenon sharply distinguished and separated from social transmission and influences. His doctrine of the continuity of the germ plasm is, for instance, at the origin of the distinction commonly held in psychological and behavioral sciences between innate and learned behaviors. ${ }^{88}$ Although such a dichotomy has been largely criticized, one of the essential foundations for the modern study of behavior - as an innate biologically driven character or as a learned, cultural phenomenon - resides in Weismann's germ-plasm theory. Furthermore, and besides his ideas, his graphic representations of differentiation processes have also had a major influence on $20^{\text {th }}$ century's understandings and representations of the separation between social and biological processes. ${ }^{89}$ Weismann's iconographic choice of describing differentiation through cell trees assigned a confined meaning to developmental processes: differentiation takes place through unidirectional relationships, which are not open to effects or feedbacks coming from external agent as well as from lateral processes of differentiation happening across distinct branches. ${ }^{90}$ These powerful symbolic and theoretical implications of Weismannism suggest a specific origin of the epistemic separation between studies of our social belongings and the biological aspects of (human) life. The transformations of a society embodied into organic functionings and their implications for heredity are, starting from Weismann, two distinct processes that belong to different disciplinary specialties. By doing so, his work inaugurates what Meloni calls "the transcendence" ${ }^{\prime 11}$ of the social from its relationship with the organic matter of life. This 
This is a Pre-Print version of the following article:

Luca Chiapperino and Francesco Panese, 'On the Traces of the Biosocial: Historicizing "Plasticity" in Contemporary Epigenetics', History of Science, 18 November 2019, 42, https://doi.org/10.1177/0073275319876839.

1 separation, we might add, should also be highlighted as the necessary premise for the biosocial

2 reunification of our biological and social existence promised by contemporary epigenetics.

\subsection{Plasticity without (environmental) molding of the substance of heredity}

4 The 1930s and 40s witnessed a renewed interest in the relationship between phenotypes induced by the environment and biological inheritance, thus inaugurating a different interpretation of plasticity in the agenda of biology. As shown by Peterson, ${ }^{92}$ an organicist 'third way' of biological thinking proliferated across this period, which marked a departure from the alternative between mechanistic and vitalist understandings of life. In the face of such long-standing dychotomy between life-as-complex-machine and life-as-irreducible-to-molecules, thinkers of such a third way brought to the fore the importance to expand the language of biology beyond the nascent centrality of genes in different socio-political contexts. ${ }^{93}$ By opening the black box of genotypeto-phenotype transitions and pointing to development as a key process in evolution, these scientists attempted to reconcile the novel episteme of genetics with a complex understanding of organisms, their environments and their mutual interactions. Chiefly, this was the case of Conrad Hal Waddington (1905-1975). ${ }^{94}$

Waddington's famous epigenetic landscape ${ }^{95}$ is a "representation of development as a system, whose parameters are genetic loci and whose state space is a set of phenotypic states." Developmental processes are represented in Waddington's landscape as a ball rolling down the landscape whose trajectory is influenced by the (genetically determined) shape of the cliff. It is thus the whole conformation of the landscape (qua developmental system) and not any single element (i.e. any single gene) giving it shape, which is at the basis of a phenotypic change. This is illustrated in the less popular "underside of the epigenetic surface" (Figure 3).

Waddington's view of genetic plasticity consists of the capacity of a complex system not to be affected by change in any of its single genetic components. Under this interpretation, plasticity is rather a property of the structure of the system itself. This is the basis of his concept of 'canalisation;' namely, the capacity of the genome to attain a given developmental outcome in light of environmental as well as genetic perturbations. Here, again, the author mobilizes the model of the landscape to illustrate this concept: 
This is a Pre-Print version of the following article:

Luca Chiapperino and Francesco Panese, 'On the Traces of the Biosocial: Historicizing "Plasticity" in Contemporary Epigenetics', History of Science, 18 November 2019, 42, https://doi.org/10.1177/0073275319876839.

sides steep, it will be more difficult to push the trajectory away from its normal course and it will quickly return there. ${ }^{97}$

Waddington was not only convinced that canalization could explain phenotypic development, but he argued also for its evolutionary potential: adaptive reaction to "unusual circumstances" may in fact cause an "adaptive character [to become] so far canalised that it continue[s] to appear even when the conditions [return] to the previous norm." ${ }^{, 98}$ In the paper just cited - published under the suggestive title "Genetic Assimilation of an Acquired Character" - Waddington reported the data from a study he conducted in Drosophila melanogaster. The results of this paper display what he calls genetic assimilation; namely, the process through which an acquired character (i.e. a variation acquired during one's lifetime) could become an inherited one (i.e. a fixed, genetically assimilated variation). The experiment went as follows. After the administration of a heat shock to the pupae of a wild Edinburgh strain of fruit flies, a number of crossveinless specimens appeared with a certain variation, which were classified according to grades of 'crossveinlessness' based on the disturbances observed in the formation of the crossveins. Two lines of selection were put in place: upward selection in which only crossveinless flies were bred, and downward selection which encompassed only flies still showing normal wings. After a further selection to reduce genetic variability among the bred flies, the results obtained by Waddington were that flies from the upward selected line started to display crossveinless wings even in the absence of the heat shock.

Yet, Waddington did not interpret these results as supporting any form of neo-Lamarckian adaptation. ${ }^{99}$ Indeed, and contrary to what some of his contemporaries believed, ${ }^{100}$ his reading of the data can be thoroughly inscribed within a neo-Darwinian framework. His interpretation of these experiments was that the response to the stimulus observed was due to selection occurring at the level of the allelic variants present in the population under study. Simply put, selection in the upward line acted on the distribution of those alleles coding for the crossveinless phenotype raising them up beyond a threshold of frequency allowing the rest of the genome to code for normal wings. As argued by theoretical biologists Eva Jablonka and Marion Lamb:

\footnotetext{
In more modern terms we would say that the variations being selected were the result of different combinations of the alleles of the many genes that are involved in the regulation of development; as a result of selection, the frequency of the initially rare combinations that contribute to an enhanced response to the stimulus increased. Eventually, selection resulted in the production of those originally extremely rare combinations that produce the crossveinless phenotype even in the absence of the temperature stimulus. ${ }^{101}$
}

However, Waddington's attempt to reconcile the hypothesis of acquired characters with one of the main pillars of the Modern Synthesis (i.e. that Darwinian natural selection acts upon variation 
This is a Pre-Print version of the following article:

Luca Chiapperino and Francesco Panese, 'On the Traces of the Biosocial: Historicizing "Plasticity" in Contemporary Epigenetics', History of Science, 18 November 2019, 42, https://doi.org/10.1177/0073275319876839.

1 of Mendelian genes) had little influence (at least in genetics) for several decades. ${ }^{102}$ As the

2 Synthesis evolved "toward a conservative centre, with little room for more creative and complex

3 ideas," ${ }^{103}$ his views were received as a revival of Lamarckism, now viewed as a threat for both

4 theoretical and political reasons. At a theoretical level, his interpretation of the crossveinless flies

5 experiment was at odds with the genetic preformationism to which many of his contemporaries

6 adhered. His view that genes do not define the emergence of a trait - but rather represent a set of

7 potentialities to be alternatively transformed into different phenotypes depending on

8 developmental conditions - had a Lamarckian flavor that contrasted with the received

9 deterministic view of genotype-to-phenotype transitions. ${ }^{104}$ At a political level, explaining the demise of Waddington's plasticity thinking requires taking into account the rise of Lysenkoism in the Soviet Union and the "morality tale" associated with such a research program in the Western genetics community of the early Cold War years. The political plot orchestrated by Lysenko that led to the death of his adversary Nikolai I. Vavilov - was soon deployed as an argument against both the ideas (i.e. environmental determination of variation and inheritance of acquired characters) and the views on the governance of science (e.g. the centralized planning of science) associated to the Soviet scientist. In such a political atmosphere, Waddington's alleged Lamarckism, coupled with his left-wing political leanings, ${ }^{105}$ displayed a damning resemblance to the aberrations of Lysenkoism, which negatively affected the reception of his work in genetics circles. ${ }^{106}$

Nonetheless, his contribution can be regarded as yet another key moment in the recent history of plasticity thinking. Even though the outcome of his experiments was the inheritance of acquired characters, his ideas about the genome do not require such inheritance to generate any modification of the fundamental substance of life. While the organic memory of Haeckel, and the modifications of the germ-plasm evoked by Weismann all conceive plasticity as material inscription of the environment into life's determinants, in Waddington's work these modifications are located in a different theoretical space. Plasticity is here a property emerging from gene expression in ontogeny and from gene selection in phylogeny. Otherwise stated, plasticity in Waddington is the attribute of a complex system whose responses to perturbations do not require the material molding of the fundamental substance of heredity. Rather, adaptation and variation emerge here from a (developmental) process actualizing the several potentialities of a complex genetic machinery capable of responding to perturbations in its components and/or its environments, and of evolving across the temporalities of natural selection. 
This is a Pre-Print version of the following article:

Luca Chiapperino and Francesco Panese, 'On the Traces of the Biosocial: Historicizing

"Plasticity" in Contemporary Epigenetics', History of Science, 18 November 2019, 42, https://doi.org/10.1177/0073275319876839.

1 Furthermore, it is worth noting how Waddington's operationalization of plasticity constitutes a

2 distinct theorization of the relationship between life as biological and social phenomenon. His

3 polemical stance towards the Modern Synthesis was in fact not only dictated by a fundamental

4 disagreement around the deterministic model defended by his "preformationist" colleagues.

5 Rather, his theory of epigenesis was part of a larger philosophical project aimed at demolishing

6 the "Bifurcation of Nature," 107 as stated in the motto of the Whiteheadian organic philosophy to

7 which he subscribed. ${ }^{108}$ Waddington considered untenable a dualism of matter that considered the organism and its environment, the biological and the psychological, the mind and the body as entities characterized by distinct ontologies. The tenets of his organic philosophy constituted a 'scientific attitude'109 towards complexity that went beyond the understanding and representations of our biology. As argued by Susan Merril Squier, ${ }^{110}$ several of his writings and professional engagements consisted in an attempt to provide a unified theory of complexity useful to biology, philosophy and the arts alike. His metaphor of the landscape, the author shows, has had an scientific representations as well as landscape architecture. Waddington analogical model provided a heuristics to conceptualize systems like biological ones, but also human societies. As he points out, his organic thinking applies as well to the analysis of totalitarian political regimes, or the scrutiny of social systems as "integrated wholes" whose good depends on "the good of its individual members." ${ }^{\prime 11}$ In its wide-ranging - and often unfulfilled - ambitions ${ }^{112}$, Waddington's organicism was thus a manifesto of scientific humanism calling for the reunification of what he ironically called "prim Science" and "harlot Humanities." 113 In this respect, Waddington's ideas provide us with another instance of the ways plasticity thinking in the life sciences also opened avenues for interrogating the relationship between life as biological and social phenomenon. His organic philosophy may be regarded as an ante litteram precedent to the contemporary quest for integrative biosocial approaches to the study of health and disease that could move us beyond irreducible oppositions between the social and life sciences.

\section{Part 2 - The synchronic dimension: 'plasticity' in contemporary epigenetics}

So far, we have identified four distinct conceptualizations and operationalizations of plasticity across the $19^{\text {th }}$ and $20^{\text {th }}$ centuries. First, we have witnessed the appearance of a paradigm of chemical modification of the body in the case of $19^{\text {th }}$ century French hygienists. According to them, health and disease must be understood as deviations from a normal state caused by the porosity of the inner functionings of our bodies to a given (chemical, social and political) milieu. Second, in 
This is a Pre-Print version of the following article:

Luca Chiapperino and Francesco Panese, 'On the Traces of the Biosocial: Historicizing "Plasticity" in Contemporary Epigenetics', History of Science, 18 November 2019, 42, https://doi.org/10.1177/0073275319876839.

1 the examination of theories of organic memory, and most notably Haeckel's perigenesis of the

2 plastidule, we could identify uses of plasticity as explanandum for the modifications of life substrates in

3 development and evolution. Plasticity here accounts for the reproduction of species-specific traits

4 as well as adaptations with evolutionary impact. Third, in the analysis of Weismann's doctrine of

5 the continuity of the germ-plasm, we have seen how a fundamental distinction was put in place at

6 the end of the $19^{\text {th }}$ century between changes happening at the somatic level and those affecting

7 the germinal lineage. Weismann's views, we showed, were less doctrinal than it has often been

8 assumed and moved the understanding of plasticity from the process of molding the vital

9 substratum (in both ontogeny and phylogeny) to a mechanistic process in need of explanation. Fourth, in the case of Waddington's notions of 'canalization' and 'genetic assimilation,' we observed how plasticity became the property of a developmental system that is capable of processing environmental signals and is governed by the laws of natural selection. According to Waddington, plasticity has to be understood as responsive potential of the genome to resist perturbations.

In this section, we turn these four historically-situated understandings of plasticity into an analytical grid to distinguish distinct epistemic approaches to body-environment relationships, development and inheritance in contemporary epigenetics. The history of $20^{\text {th }}$ century epigenetics consists of a number of cognate endeavors that, while affirming a common affiliation to Waddington, often pursue research programs that stand in open contrast with one another. ${ }^{114} \mathrm{~A}$ uniform characterization of the fundamental epistemological tenets of this scientific field is a hard task, ${ }^{115}$ and also representations of epigenetics in public discourses are often fragmented or contradictory. Recognizing that historical work on epigenetics could illuminate its plural epistemologies, ${ }^{116}$ in this section we describe few discrete understandings of plasticity across various sub-fields of epigenetics such as epigenomics, behavioral/environmental epigenetics, and epigenetic epidemiology/exposomics. Our analysis does not aim to systematically classify all distinct usages of plasticity in contemporary epigenetics, but rather to provide a few situated examples of how this notion entertains distinct theoretical stances and experimental practices within this domain. As we shall see, the four distinct historically-situated understandings of plasticity we isolated above can be helpful to characterize and distinguish the diverse explanatory functions of this notion in contemporary epigenetics. 
This is a Pre-Print version of the following article:

Luca Chiapperino and Francesco Panese, 'On the Traces of the Biosocial: Historicizing

"Plasticity" in Contemporary Epigenetics', History of Science, 18 November 2019, 42, https://doi.org/10.1177/0073275319876839.

\section{$1 \quad 2.1$ Plasticity in epigenomics}

2 A substantial part of research funding in epigenetics currently falls under the label of

3 'epigenomics', which exploits the power of next-generation sequencing to map the epigenetic

4 patterns (i.e. epigenomes) characterizing the diverse tissue types in our bodies. Reference human epigenomic maps are currently a free resource available to researchers interested in the study and comparison of the epigenetic differences that characterize hundreds of cell types in a 'normal' or 'aberrant' state. ${ }^{117}$ A closer look at these maps reveals that this strand of epigenetic research employs and operationalizes an understanding of plasticity as the capacity of the genome to produce a diverse range of phenotypes. The epigenome is here characterized as a series of steady state conformations of the genome that are specific to distinct types of cells in the body, and to the transitions between health and disease in a given tissue. In its current and most advanced formulation, epigenomic data are a multi-layered description of the "epigenetic plasticity that enables cells to undergo [a] wide range of [cellular] lineage specifications." ${ }^{\text {118 }}$ From chemical modifications of DNA not affecting the sequence (e.g. methylation), to modifications of the proteins around which DNA is compacted into chromatin (e.g. histone modifications), up to higher-level reshufflings of nuclear architecture, epigenomic maps integrate different snapshots of the material operators of regulation and expression of the genome in a complex representation. Plasticity in epigenomics is thus a distinctive combinatorial notion; namely, the result of distinct layers of genomic activity acting in concert to determine complex phenotypes, specifications, and transitions in the cells of our bodies. The different material operators of genomic differentiation (e.g. methylation, histone modifications, nucleosome positioning) build upon and extend the information potential of DNA in order to craft the diverse phenotypic characteristics of each cell type. The epigenetic profile of any given cell is in fact the result of programmed DNA arrangements, which unfold into the material structuring of distinct layers of combinations among DNA, RNAs, histones, and chromatin modifications in the nuclear genome of a cell.

Epigenomic maps permit us to describe a first conceptualization and operationalization of plasticity in contemporary epigenetics. Our genome is here regarded as a developmental resource, which possesses the capacity to unfold into various epigenomic potentials - being these the different cell types of the body, or the molecular configurations of a diseased tissue. In this respect, plasticity in epigenomics is continuous with the intellectual program of authors such as Waddington. ${ }^{119}$ At the same time, the idea of genetic control of phenotypic plasticity in 
This is a Pre-Print version of the following article:

Luca Chiapperino and Francesco Panese, 'On the Traces of the Biosocial: Historicizing "Plasticity" in Contemporary Epigenetics', History of Science, 18 November 2019, 42, https://doi.org/10.1177/0073275319876839.

1 epigenomics appears to be imbued also with Weismannism as interpreted by the 'central dogma'

2 of molecular biology. ${ }^{120}$ Respectively, epigenomics goes along the same track of plasticity thinking

3 à la Waddington in that it postulates the differentiation from the zygote to the whole range of

4 tissues in our body (both healthy and diseased) to be captured by a panoply of steady-state

5 cartographies of the (normal or pathological) epigenetic signatures of each different cell type. In

6 short, epigenomic maps describe, in a Waddingtonian fashion, the behavior of the genome as a

7 complex developmental system crafting a given phenotype. At the same time, epigenomic scientists provide an understanding of plasticity which is essentially (i) on the side of the soma by the standard of Weismann's barrier, and (ii) an intrinsic genetic property that flows from DNA to combinations of gene expression, conformations of regulatory regions and genomic architectures of cells. In fact, plasticity is here on the side of soma because epigenomics postulates that cellular differentiation belongs to phenotypic development and does not contribute to modifications of the fundamental substance of heredity. In line with the 'doctrine of the continuity of the germplasm', plasticity in epigenomics is postulated as a transfer of sequential information between levels of genomic regulation, which does not involve any transmission of acquired information across the germ line. Furthermore, the interpretation of plasticity in epigenomics is also deeply imbued with the paradigm inaugurated by classical quantitative genetics as it postulates that genetic variations are the main material operator of cellular differentiations from healthy to diseased states. State of the art epigenomic maps take in fact genetic variation both as a 'difference maker" ${ }^{\text {'121 }}$ of the transition from normal to aberrant epigenomic states, and as the 'trait maker ${ }^{122}$ constituting the epigenetic profile that characterizes the phenotype of a given tissue. It is quite telling, in this respect, that the word 'plasticity' occurs in the special issue of Nature comprising the first hundreds of epigenomic maps only in two specific contexts. Firstly, in relation to the effects of genetic variation on the architectural arrangements of chromatin, ${ }^{123}$ and secondly in the context of the quantitative analysis of downregulated genes for "synaptic plasticity" in Alzheimer's disease. ${ }^{124}$

\subsection{Plasticity in behavioral and environmental epigenetics}

Researchers in fields such as 'behavioral epigenetics' and 'environmental epigenetics' address the question of plasticity as "signals from the environment" that "trigger molecular biological changes." 125 Differently from epigenomic maps, these studies have provided an understanding of how exposures to toxic substances ${ }^{126}$ as well as stressful conditions ${ }^{127}$ can trigger germ-linemediated inheritance of epigenetic predispositions for behavioral patterns or health conditions. 
This is a Pre-Print version of the following article:

Luca Chiapperino and Francesco Panese, 'On the Traces of the Biosocial: Historicizing "Plasticity" in Contemporary Epigenetics', History of Science, 18 November 2019, 42, https://doi.org/10.1177/0073275319876839.

1 In so doing, behavioral or environmental epigeneticists postulate a very precise role for plasticity,

2 which amounts to the embodiment of environmental conditions in phenotypic development and

3 heredity. These scientists hypothesize that the social environment (especially at early stages of

4 life) has a long-term impact on mental and physical conditions via the imprinting of epigenetic

5 signatures. ${ }^{128}$ The biology of complex traits (e.g. stress-coping, fear, fertility) is to be explained,

6 under this view, by the mutual shaping of genes and their environment (from experiences, to

7 exposures, to genes and back to phenotypes and behaviors).

8 In a remarkable revival of ancient ideas of organic memory, such as Haeckel's theory of the

9 'perigenesis of the plastidule,' these epigenetic scientists advance a programmatic effort to dissect mechanistically how the plasticity of our genome entails environmental modifications of the very substance of development and heredity. As argued by Moshe Szyf, a prominent actor in this field, processes of epigenetic programming triggered by environmental stimuli take place over blurred temporalities of ontogeny and phylogeny:

If multigenerational transmission of ancestral experiential memory evolved to increase survival and fitness, such a mechanism should be able to modulate phenotypes crucial for survival [...]. It is plausible then that nongenetic inheritance would function at different timescales depending on the nature of the ancestral experience. Maintaining plasticity in response to dynamic environments requires generationlimited and reversible reprogramming. By contrast, a permanent change in habitat requires a stable multi-generational phenotypic transformation. ${ }^{129}$

Indeed, behavioral and environmental epigeneticists have even gone further in paralleling Haeckel's ambition to integrate ontogeny and phylogeny, as well as Lamarckian and Darwinian evolution in the conceptualization of their epistemic work. ${ }^{130}$ According to Szyf, ${ }^{131}$ the disputed ${ }^{132}$ possibility that environmental exposures could produce transgenerational adaptations via epigenetic programming (in the absence of genetic change) is a vindication of Lamarckism. In his view, the idea of the inheritance of acquired characters has been marginalized due to the lack of a plausible mechanism serving as "conduit between the environment and stable alteration of gene function that could be stably transmitted through the germline."133 Evidence of epigenetic inheritance via the gametes provides such a mechanism, thus suggesting that evolution (in a neoDarwinian sense) has equipped organisms with "mechanisms to respond specifically and efficiently to certain critical novel experiences," and "to transmit this information effectively to their offspring" without necessarily involving "the typically slow process of natural selection." In a nutshell, the plasticity of epigenetic marks enables the author to argue that Darwinian evolution has crafted at least one mechanism for Lamarckian evolution to occur. 
This is a Pre-Print version of the following article:

Luca Chiapperino and Francesco Panese, 'On the Traces of the Biosocial: Historicizing "Plasticity" in Contemporary Epigenetics', History of Science, 18 November 2019, 42, https://doi.org/10.1177/0073275319876839.

1 In contrast, another influent environmental epigeneticists such as Michael Skinner argues that environmental epigenetics and transgenerational epigenetic inheritance provide grounds for integrating another "neo-Lamarckian concept" 135 into the Neo-Darwinian theory of evolution. His ideas build upon the substantial corpus of epigenetic research dissecting the involvement of epigenetic processes in disease aetiology. These studies show how epigenetic mechanisms (most notably, DNA methylation) can promote genomic instability and induce genetic mutations. What emerges then as epi-mutation transmitted to the progeny has, in Skinner's understanding, also a role in producing genetic changes and variations that in turn are subjected to natural selection. This way, the author can claim a dual role for epigenetic processes in evolution: one (that we encountered in Szyfs work) pointing to the transmission of acquired phenotypic characters through germline-mediated epigenetic inheritance. The other, instead, pointing to the role of these epigenetic mechanisms in inducing mutations on which natural selection intervenes subsequently. Briefly put, epigenetics enables the author to postulate that a neo-Lamarckian mechanism could be the driver of neo-Darwinian evolution.

Interestingly, neither a direct reference to past theories of organic memory, nor the etymologically dense terminology of Haeckelian heritage can be found in the academic production of these authors ${ }^{136}$. Both authors inscribe instead their views as standing in continuity with those of Waddington, who is acknowledged in their writing not just as the originator of the field of epigenetics, but as a forerunner of studies of plasticity as mechanism of non-genetic inheritance ${ }^{137}$. The word 'plasticity' is explicitly problematized in only one of the texts analyzed above $^{138}$, although it occurs extensively elsewhere in these scientists' production, ${ }^{139}$ and it is often equated with "epigenetic alterations" 140 and "molecular mechanisms" environment on inherited biological traits. We thus see at play here how the epistemic space ${ }^{142}$ of contemporary epigenetics harbors distinct and often unacknowledged traditions of plasticity. While scientists' narratives of the field and its epistemological foundations refer to Waddington to reinforce the idea of a common origin of its different epistemic programs, a thorough scrutiny of the conceptualizations and operationalizations of plasticity in this field suggests a different reading. Drawing from the four distinct historically-situated understandings of plasticity we isolated above, it is in fact possible to characterize how this notion instructs distinct conceptual and experimental endeavors across different corners of epigenetics. At a closer look, plasticity in environmental and behavioral epigenetics seems to have little in common with the way this notion was conceptualized and experimented with in Waddington's work, or the way it is currently being interpreted in the field of epigenomics. Rather, plasticity seems to be bestowed 
This is a Pre-Print version of the following article:

Luca Chiapperino and Francesco Panese, 'On the Traces of the Biosocial: Historicizing "Plasticity" in Contemporary Epigenetics', History of Science, 18 November 2019, 42, https://doi.org/10.1177/0073275319876839.

1 here with the capacity to account for the very same molding of the fundamental substance of

2 heredity, which was a fundamental facet of its interpretation in Haeckel and that is still required -

3 in these authors' view - to explain a common biological basis for ontogeny and phylogeny.

42.3 Plasticity in molecular epidemiology and exposomics

5 A similar style of reasoning informs those research designs currently encompassed by the labels of 'molecular epidemiology' or 'epigenetic epidemiology.' These approaches - "marrying a bench

science and a population science" - aim at identifying the "mechanistic link between environmental exposures and diseases outcomes." ${ }^{143}$ Some molecular epidemiologists adopt a life-course perspective to address questions regarding the relationship between socio-economic status and epigenetic biomarkers for susceptibility to disease. ${ }^{144}$ Some others focus instead on development and highlight the importance of epigenetics to understand early-life exposures leading to adult diseases under the overarching hypothesis of the "Developmental origins of health and disease-DOHaD." ${ }^{145}$

During the critical periods of ontogenesis, [environmental] influences result in modifications connected with ontogenetic plasticity that lead to permanent changes in structure and function of different organs and systems of an organism..$^{146}$

Among the various ways of experimenting with body-environment plasticity and permeability in molecular epidemiology, the concept of 'exposome' has been recently gaining traction. ${ }^{147}$ The exposome heralds a turn in the relationship between epidemiological sciences and molecular biology. First, exposomics widens the breadth of molecular approaches in epidemiology by postulating different levels of genomic regulation and expression (e.g. metabolomics, proteomics) beyond the epigenome as concurring "biosensor[s]" that modulate body-environment interactions and "hence trigger disease." ${ }^{148}$ Second, exposomics opens up molecular epidemiology to a detailed characterization of the chemical interactions between the body and its surrounding material and social environments. ${ }^{149}$ The exposome is supposed to counter a strict focus on genomic plasticity as the main explanandum of disease aetiology through the association of genetic variants with health outcomes in the population. ${ }^{150}$ The problem with these studies, according to exposomic scientists, is a consideration of disease causation as a genetic phenomenon. This approach, they argue, proved unable to explain how diseases develop given the prominent role of environmental exposures in producing a given phenotype. For this reason, exposomic studies revolve around a measurement of the entire set of exposures to which individuals are subjected from conception onwards throughout their lifespan. ${ }^{151}$ Such a concept stresses therefore the importance of measuring the environment in its totality (from environmental pollutants to work- 
This is a Pre-Print version of the following article:

Luca Chiapperino and Francesco Panese, 'On the Traces of the Biosocial: Historicizing

"Plasticity" in Contemporary Epigenetics', History of Science, 18 November 2019, 42, https://doi.org/10.1177/0073275319876839.

1 related exposures and lifestyles over the life-course) and to complement this measurement of the "external" environment with a characterization of the "internal chemical environment" where the external environment gets processed into the metabolic functioning of the body. ${ }^{152}$ Thus, the exposome is conceived as an epistemic tool describing the biochemical processes linking the body with its surroundings, the genomic predispositions with the "endogenous and exogenous chemicals in the body at [any] given time." ${ }^{\prime 153}$ Researchers in this field stress the need to combine knowledge from classical epidemiological methods (e.g. exposure matrices, dietary recalls) with a characterization of 'downstream' biological events such as analyses of the chemical compounds circulating in bodily fluids (e.g. blood ${ }^{154}$ ), or the modifications of gene expression brought about by epigenetic changes. ${ }^{155}$ The complementarist view of exposomic studies is that the role of the environment in disease development should be reduced neither to a disturbance of a geneticallydriven process (like in epigenomics) nor to the effects of one exposure (like in behavioral or environmental epigenetics). Rather, exposomics encourages taking the plastic cross-talk between environments and the genome - the "molecular conduit" between the inner and the outer ${ }^{156}$ - as a whole, multi-layered biochemical process by which the environment enters the body.

As illustrated by a recent and influential issue of the International Journal of Epidemiology (IJE), scientists across these various strands of molecular epidemiology (re)construct the history of their field against the backdrop of Waddington's work. The issue revolves around a reprint of Waddington's 1943 paper 'The Epigenotype' and is presented as both a celebration of the importance of his ideas for the field and an overview of the various approaches that follow his ideas in epidemiology. Besides the reprint of 'The Epigenotype,' the issue includes in fact also: a series of commentaries on the legacy of Waddington's work for epigenetic epidemiology written by renowned evolutionary and theoretical biologists; ${ }^{157}$ a number of theoretical and empirical papers that deal with the import of epigenetics for the study of prominent epidemiological questions (e.g. the association between socio-economic status and health inequalities); ${ }^{158}$ a review on the translation of exposomic approaches into concrete research programs; ${ }^{159}$ as well as a symposium around the book by Patrick Bateson and Peter Gluckman on plasticity thinking in epidemiology across development and evolution. ${ }^{160}$ No doubt, conceptualizations of plasticity in molecular epidemiology present several analogies with its Waddingtonian interpretation analyzed above. Like Waddington, these scientists conceive and operationalize biological plasticity as the set of causal mechanisms that intervene between the genotype and the phenotype during the lifecourse. Furthermore, epigenetic epidemiology views of plasticity are also grounded on an 
This is a Pre-Print version of the following article:

Luca Chiapperino and Francesco Panese, 'On the Traces of the Biosocial: Historicizing

"Plasticity" in Contemporary Epigenetics', History of Science, 18 November 2019, 42, https://doi.org/10.1177/0073275319876839.

1 through complex processes at the crossroad of gene regulatory networks and environmental

conditions. ${ }^{161}$ Yet, the construction of this historical trajectory from Waddington to present molecular epidemiology also obliterates some major differences between the reflections around plasticity animating this field and those purported by the British biologist. Of note, molecular epidemiologists are only partly concerned with processes of embryogenesis and development as a matter of evolutionary significance. With the exception of some epidemiological approaches grounded on DOHaD hypothesis ${ }^{162}$, the majority of scientists in this domain rather focus on the modifications to which individual bodies are subjected from conception to the adult age.

Furthermore, Waddington's epigenotype provides only a limited ground to cast developmental processes and complex genotype-to-phenotype transitions as open to environmental stimuli. As acknowledged also by the editorial introducing this special issue of IJE, this particular paper of his "says nothing about environmental modifiers of gene expression." 163

In this respect, the different strands of molecular epidemiology rather evoke the operationalization of plasticity animating the hygienist movement at the beginning of the $19^{\text {th }}$ century. ${ }^{164}$ As in the case of early hygienists, these researchers take the environment as a 'plastic life modifier;' namely, a variable that produces a fundamental change in biological functioning and a deviation from the normal to the pathological. Much like their $19^{\text {th }}$ century predecessors, they consider the body as an open metabolic entity penetrated and modified by the external world - incidentally reduced also here to a taxonomy of different types of exposures (see section 1.1). Yet, it is worth mentioning how at least one major difference can be found in the articulation of these two historically distant paradigms. While public hygienists black-boxed the inner workings of the reciprocal modulations of bodies and environments, molecular epidemiologists attempt to unfold the fundamental mechanisms of this process thanks to an approach that draws from various facets of contemporary biology. The problem for the French hygienists was in fact less dissecting individual differences in the chemical interactions between bodies and milieu than the recognition of a social problem equally affecting every citizen's body as normal metabolic entity. By contrast, contemporary molecular epidemiologists render vivid the chemical continuum in which the body and its inner working stand with respect to the exposures to which it is subjected. In brief, the metabolic body of molecular epidemiology is no longer an organic substrate that is essentially the same for everyone, but rather a multi-layered molecular entity that combines unique genetic and metabolic predispositions with exposures and chemical alterations specific to one's material and social environment. 
This is a Pre-Print version of the following article:

Luca Chiapperino and Francesco Panese, 'On the Traces of the Biosocial: Historicizing

"Plasticity" in Contemporary Epigenetics', History of Science, 18 November 2019, 42, https://doi.org/10.1177/0073275319876839.

1 Discussion. Plasticity, epigenetics and the biosocial.

2 Our historical and epistemological analysis of 'plasticity' illuminates several differences in the

3 general mind-sets and the concrete research accounts mobilizing this notion in contemporary

4 epigenetic biosciences. Current mobilizations of this notion as explanandum for phenotypic and

5 (potentially) evolutionary adaptations present several analogies with distinct conceptualizations

6 and operationalizations across the last two centuries. This is not meant to deny that $19^{\text {th }}$ and early

$7 \quad 20^{\text {th }}$ centuries debates seeking to explain the plastic development and evolution of organic forms

8 have given rise to traditions that strongly contrast with one another. ${ }^{165}$ Far from constituting an

exhaustive reconstruction of the historical and epistemological complexities of biological thinking

in the last two centuries, the different trajectories we drew are meant only to historicize and

distinguish the modes of understanding body-environment relationships in contemporary epigenetics. Specifically, drawing these historical parallels can (i) reveal major differences among uses and conceptions of plasticity internal to epigenetic life sciences; (ii) highlight how the fundamental disagreements animating plasticity thinking across the $19^{\text {th }}$ and $20^{\text {th }}$ centuries have persisted until today; and (iii) position the diverse epistemologies of plasticity in epigenetics with respect to the ways this notion enables the production of a biosocial understanding of (human) life. ${ }^{166}$

First, our work provides several entry points on the diverse explanatory functions that plasticity plays in the synchrony of current epigenetic biosciences. As shown above, researchers from different sub-fields of epigenetics often turn to Waddington to construct themselves as heirs of a past in which the gene was not the sole and ultimate source of biological information. ${ }^{167}$ Yet, our analysis demonstrates how variegated is the economy of concepts, causal explanations and experiments afforded by plasticity thinking in contemporary epigenetics. Without the need to read these differences in the present as the actual confrontation among the distant traditions we explored above, our analysis illuminates the epistemological gaps among co-existing views of plasticity in epigenetics.

The analogies we drew in our work underline in fact that the controversies internal to the field of epigenetics may be due more to a fundamental epistemological disagreement around views of plasticity, than the alleged lack of evidence in support of any of the different approaches populating this field. Clearly, molecular epidemiologists and behavioral/environmental epigeneticists share with their predecessors grappling with hypotheses of 'organic memory' a notion of plasticity committed to an understanding of the molecular patterns that allow the environment to mold the 
This is a Pre-Print version of the following article:

Luca Chiapperino and Francesco Panese, 'On the Traces of the Biosocial: Historicizing "Plasticity" in Contemporary Epigenetics', History of Science, 18 November 2019, 42, https://doi.org/10.1177/0073275319876839.

1 substance of development and heredity. In so doing, both of these approaches counter the

2 interpretation that is common within epigenomic research. Epigenomic scientists understand

3 instead plasticity as a combinatorial property of genetically-driven networks of development.

4 Thus, while in the former cases plasticity mediates a traffic between the internal and the external

5 and affords a mnemonic capacity of the body, the latter takes the environment as a signal to be

6 processed by a complex genetic system. ${ }^{168}$ Hence, within epigenomics, plasticity is the

7 actualization of a systemic potential of the genome to give shape to a phenotype. In

8 behavioral/environmental epigenetics and molecular epidemiology, instead, plasticity stands for

9 the capacity of the genome to be permeable to its environments. ${ }^{169}$ Yet, major conceptual differences as to how plasticity should be characterized, understood and mobilized as an experimental resource exist also between these two sub-fields of epigenetic sciences. On the one hand, behavioral and environmental epigeneticists construct a model of a given 'environmental phenomenon' (e.g. pesticide exposure) by specifying thresholds of 'good' or 'bad' stimuli, in order to suggest a causal relationship between such stimuli, an epigenetic state (e.g. the methylation patterns of a certain gene), and a given phenotype (e.g. fertility). ${ }^{170}$ Thus, these approaches display an understanding of plasticity as a means by which an external phenomenon (e.g. chemicals, nutrients, stress, etc.) gets materially engraved into our genome through specific molecular mechanisms. On the other hand, molecular epidemiologists - especially in the field of exposomics - multiply the complexity of such "molecular conduit"171 by stratifying the totality of environmental exposures as a cumulative source of causality in life-course health trajectories. In this vein, plasticity is the permeable feature of the body and not simply the mnemonic capacity of the genome; that is, it is the feature of an organic system whose unique inner workings chemically intertwine with those of a neo-hygienist milieu.

We can thus elaborate here on how our historico-epistemological analysis unveils a fundamental epistemological disagreement around plasticity in contemporary epigenetics. As argued by Ute Deichmann, ${ }^{172}$ contemporary epigeneticists part over the interpretation of epigenetic modifications of gene expression. To some, epigenetic changes are the result of modifications mediated by sequence-specific transcription factors. According to this view - predominantly popular among epigenomic scientists - what other epigeneticists ascribe to environmental 30 influences (like in molecular epidemiology), or to an alleged mnemonic capacity of the genome (as in behavioral/environmental epigenetics) is instead due to specificities of the transcriptional machinery and individual DNA sequence variability. ${ }^{173}$ By affecting the accessibility of the genome, genetic factors - and not epigenetic modifications - are the mediators of changes in 
This is a Pre-Print version of the following article:

Luca Chiapperino and Francesco Panese, 'On the Traces of the Biosocial: Historicizing "Plasticity" in Contemporary Epigenetics', History of Science, 18 November 2019, 42, https://doi.org/10.1177/0073275319876839.

gene expression. According to others, the causal primacy between epigenetic and genetic factors has instead to be inverted: regulatory changes stem from the epigenetic modification itself. This view, common in the two camps of molecular epidemiology and behavioral/environmental epigenetics, points instead to the potentially paradigm-shifting aspects of epigenetic findings. Chemical modifications of DNA and its structure are, in this view, an additional layer of information that links the genome to its material and social environments. Otherwise stated, these researchers question the idea of the genome as first cause, and argue against a gene-centric view of development, life-course health trajectories and (potentially) evolution. ${ }^{174}$ In fact, another point of controversy relates to the temporal frames in which these modifications are taken to operate. According to some, epigenetic modifications are confined to mitosis; namely, the process of cellular reproduction in development, growth and tissue regeneration. According to others, instead, epigenetic modifications extend beyond cell division to constitute mechanisms of heredity and evolution. ${ }^{175}$

Most of the definitions of epigenetics today do not distinguish between these different phenomena, ${ }^{176}$ thus allowing this plurality of views to thrive under the same ambiguous heading.

Concomitantly, however, a strong skepticism about what biological phenomena count as epigenetic ones polarizes the various sides of this controversy. Several actors ${ }^{177}$ and commentators ${ }^{178}$ in the field invest the need for "hard data" as a potential solution to the reciprocal skepticism that has set among these different approaches in epigenetics. Yet, our analysis suggests that these confrontations rather play out as divergent conceptualizations of plasticity, which have implications for the definition of the scope and epistemic priorities of epigenetics. While cautionary tales about the inconclusive nature of epigenetic studies may serve 3 the aspiration of an all-encompassing definition of the field, our work underlines that hard data 4 may not deliver the synthesis among these divergent views. Quite the contrary, our analysis 5 provides evidence to doubt that conceptions of plasticity holding capable epigenetic marks to 6 bear the material impression of the environment may be reconcilable with those view of this 7 notion that place it under a strict genetic control.

8 Second, our historico-epistemological analysis of plasticity provides a particularly illustrative 9 entry-point to the enduring nature of the economy of concepts, experimental designs, and 30 biological theories animating the field of epigenetics today. Otherwise stated, it details how - as 1 recognized also by others ${ }^{179}$ - the cardinal question of how to account for the reciprocal 32 modulation of organic substrates and their contexts of development has persisted throughout 
This is a Pre-Print version of the following article:

Luca Chiapperino and Francesco Panese, 'On the Traces of the Biosocial: Historicizing

"Plasticity" in Contemporary Epigenetics', History of Science, 18 November 2019, 42, https://doi.org/10.1177/0073275319876839.

1 major changes in the scientific concepts and the experimental cultures of biological thinking. This recognition allows us to cast a critical gaze on the supposed novelties attributed to epigenetics. Looking at the recent history of biology through the lens of plasticity indicates that current questions in epigenetics - concerning the role of the environment for development, heredity and evolution - are continuous with the history of biology as a discipline. In this respect, our work calls into question the idea that contemporary biology has moved from gene-centrism towards a more holistic understanding of life. ${ }^{180}$ Contrary to this popular reading of epigenetics as the purveyor of a 'revolution' in the life sciences ${ }^{181}$, our work shows that thinking of the 'gene' as devoid of any interaction with its environments is more a rough simplification of the recent history of biology than a monolithic stance of any recent time in this domain. ${ }^{182}$ The 'chemical body' of French public hygienists, the 'plastidule' in Haeckel, the 'germ-plasm' in Weismann, the 'genotype' in Waddington - to name the representative few we mobilized - represent several examples of how the life sciences have constantly attempted to come to terms with the multiple, complex and ecological elements of the development of forms of living.

Third, this points to a further finding that relates to the biosocial openings offered by contemporary epigenetics. The possibilities epigenetics offers to think about the hybridities between our biological and social existence are at the center of much attention on the part of social scientists. ${ }^{183}$ As we have seen, the heuristic function of plasticity in its diachronic development went beyond a simple attempt to make sense of the reciprocal modulation of organic substrates and their environments in ontogeny and phylogeny. Operationalizations of plasticity thinking in the $19^{\text {th }}$ and $20^{\text {th }}$ centuries constituted also the material and factual resources to imbue knowledge of the body with coeval socio-political contexts. As shown above, plasticity thinking provided a vocabulary of mechanisms, imaginaries and explanations that resonated across social spaces as cultural and symbolic objects. Plasticity thinking testifies, in other words, of different modalities to conceive the processual engagements and social embeddedness of our biology. Within the historical instances we have briefly analyzed, plasticity enabled understandings of social progress, of the unity between biological and social phenomena as well as provided a ground for political action. In brief, a historical epistemology of biological plasticity offers the possibility of identifying traces of biosocial thinking in the past, and raises the question of how these multiple facets of the biosocial are re-interpreted within contemporary debates. As shown by Jorland, ${ }^{184}$ the institutionalization of the chemical episteme of $19^{\text {th }}$ century hygiene in France related to a conception of liberal biopolitical action that framed humans as biological and social beings. The hygienist concern with the government of population health thus points to 
This is a Pre-Print version of the following article:

Luca Chiapperino and Francesco Panese, 'On the Traces of the Biosocial: Historicizing

"Plasticity" in Contemporary Epigenetics', History of Science, 18 November 2019, 42,

https://doi.org/10.1177/0073275319876839.

1 strategies of intervention over the biological and social factors of health and disease. ${ }^{185}$ Haeckel's

2 theory of organic memory was concerned - like present debates around the biosocial - with the

3 difficulty to find a common ontology for psychosocial and biological aspects of life. This

4 recognition underlines the need for a critical uptake of the synthesis between the biophysical and

5 sociocultural conceptions of human existence in current post-genomics: ${ }^{186}$ what if the ontology of

6 the biosocial emerging from the increasing convergences between social and biological sciences is

7 flattened to the one-category ontology of biochemistry dominating the life sciences? The role of

8 Weismann's experiments in forging a separation of the social from the biological constitutes the

necessary premise on which calls for the reunification of social and biological sciences rest in the

present of the biosocial age. ${ }^{187}$ In doing so, Weismann's work reminds us of the historical

sedimentation of the bio-social divide, and of the barriers and difficulties that may be faced in

restoring an integrative biosocial epistemic approach. How to avoid the potential

molecularization of our social understanding of life that could arise from contemporary biology's style of reasoning? ${ }^{188}$ And, at the same time, how to reconcile "hard-won evidence that could save our lives" with the social constructivist view that is popular among the social sciences? ${ }^{189}$ The need to produce an integrative biosocial science in the present of post-genomics ${ }^{190}$ may thus require weaving a philosophical filigree that departs from present worldview in the social and life sciences. This view, open to complexity thinking, should be capable of accounting for a shared idea of a socially situated biology. ${ }^{191}$ What is, then, the role that Waddington's attempt to achieve this goal through an organicist philosophical project may play for such an endeavor? ${ }^{192}$

As Maurizio Meloni has argued, ${ }^{193}$ it is important to recognize that the relationship between science and politics is one of fundamental underdetermination. Epistemic statements are compatible with multiple political values, and the history of biology is indeed full of adversarial uses of the same evidence in the political space - as illustrated by his thorough analysis of Lamarckism and Mendelism at the turn of $20^{\text {th }}$ century. To this point, our work contributes also a methodological pointer underlining the analytical potential of digging into (some of the historical contingencies ${ }^{194}$ that linked our bodies to their environments. Our historical and epistemological parallels provide a multi-layered interpretation of today's attempts to interpret the bio-social nexus that links our biology with its material, social and cultural environments. Epistemic practices around plasticity in contemporary epigenetics offer us the return of traditions, which as we have partly reconstructed here - do not align with the Waddingtonian genealogical tree (re)constructed by the epigenetic orthodoxy ${ }^{195}$. These very same traditions, we argue, offer us also the possibility to recognize distinct facets of the biosocial as: (i) ontological conceptions of the 
This is a Pre-Print version of the following article:

Luca Chiapperino and Francesco Panese, 'On the Traces of the Biosocial: Historicizing "Plasticity" in Contemporary Epigenetics', History of Science, 18 November 2019, 42, https://doi.org/10.1177/0073275319876839.

1 unity of life as social and biological phenomenon, (ii) calls for epistemic hybridity across social

2 and biological sciences, and (iii) injunctions towards biopolitical governing of our plastic bodies.

3 These different facets of the biosocial are yet to become fixed theoretical and political options in

4 the present of post-genomics. As traces of the biosocial, they could therefore serve as

5 methodological and heuristic guide for approaching critically the assumptions, values, (social)

ontologies and political leanings currently populating the field of epigenetics.

\footnotetext{
${ }^{1}$ We will not delve here into an analysis of cognate uses of 'plasticity' in contemporary neuro- and cognitive sciences. Although notions of biological and neural plasticity are certainly interwoven, here we focus on the debate that predates a consideration of functions and psychology of the brain as an epistemic space for biological and medical sciences (see: C. A. Logan, 'Engrams and Biological Regulation: What Was 'Wrong” with Organic Memory?,' Memory Studies 8, no. 4 (1 October 2015): 407-21). For an analysis of the multiple ways in which contemporary uses of plasticity in biology crosscut those in neurosciences, see: D. Papadopoulos, 'The Imaginary of Plasticity: Neural Embodiment, Epigenetics and Ecomorphs,' The Sociological Review 59, no. 3 (August 1, 2011): 432-56.

2 A.P. Feinberg, 'Phenotypic Plasticity and the Epigenetics of Human Disease,' Nature 447, no. 7143 (May 24, 2007): 433-40.

${ }^{3}$ C. Dupras and V. Ravitsky, 'The Ambiguous Nature of Epigenetic Responsibility,' Journal of Medical Ethics, 25 March 2016, medethics-2015-103295, https://doi.org/10.1136/medethics-2015-103295.

${ }^{4}$ M. Szyf, 'Nongenetic Inheritance and Transgenerational Epigenetics,' Trends in Molecular Medicine 21, no. 2 (2 January 2015): 134-44.

5 J. Niewöhner, 'Epigenetics: Embedded Bodies and the Molecularisation of Biography and Milieu,' BioSocieties 6, no. 3 (2011): 279-98.

${ }^{6}$ M. K. Skinner, 'Environmental Epigenetics and a Unified Theory of the Molecular Aspects of Evolution: A NeoLamarckian Concept That Facilitates Neo-Darwinian Evolution,' Genome Biology and Evolution 7, no. 5 (16 May 2015): 1296-1302; E. Whitelaw, 'Disputing Lamarckian Epigenetic Inheritance in Mammals,' Genome Biology 16, no. 1 (2015): 60; A. Nicoglou, 'Waddington's Epigenetics or the Pictorial Meetings of Development and Genetics,' History and Philosophy of the Life Sciences 40, no. 4 (27 September 2018): 61.

7 T. Ingold and G. Pálsson, eds., Biosocial Becomings: Integrating Social and Biological Anthropology (New York: Cambridge University Press, 2013); M. Meloni, S. J. Williams, and P. Martin, eds., Biosocial Matters: Rethinking the Sociology-Biology Relations in the Twenty-First Century, Wiley-Blackwell, Sociological Review Monograph (Chichester, West Sussex ; Malden, MA: Wiley-Blackwell, 2016); M. Meloni et al., eds., The Palgrave Handbook of Biology and Society, 1st ed. 2018 edition (London: Palgrave Macmillan, 2018); M. Meloni, Impressionable Biologies, (New York, NY: Routledge, 2019).

${ }^{8}$ S. Müller-Wille and H.-J. Rheinberger, eds., Heredity Produced: At the Crossroads of Biology, Politics, and Culture, 1500-1870, Transformations (Cambridge, Mass: MIT Press, 2007).

9 M. Pigliucci, Phenotypic Plasticity: Beyond Nature and Nurture (Baltimore: Johns Hopkins University Press, 2001); A. Nicoglou, 'The Evolution of Phenotypic Plasticity: Genealogy of a Debate in Genetics,' Studies in History and Philosophy of Science Part C: Studies in History and Philosophy of Biological and Biomedical Sciences 50 (1 April 2015): 67-76.

10 M. Meloni, Political Biology, (Basingstoke, Hampshire; New York, NY: Palgrave Macmillan, 2016); Meloni, Impressionable Biologies, ch.1; Tatjana Buklijas, 'Histories and Meanings of Epigenetics,' in The Palgrave Handbook of Biology and Society, eds. Maurizio Meloni et al., pp.167-87.

${ }^{11}$ See Meloni, Impressionable Biologies for a similar approach mobilizing pre-modern views of the plastic body.

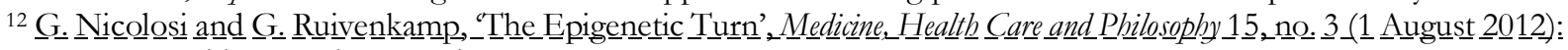

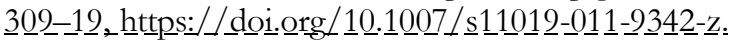

13 I. Hacking, 'Language, Truth and Reason,' in Rationality and Relativism, ed. Martin Hollis and Steven Lukes (MIT Press, 1982), 48-66.

${ }^{14}$ L. Daston, 'Historical Epistemology,' in Questions of Evidence: Proof, Practice, and Persuasion Across the Disciplines, ed. James K. Chandler, Arnold Ira Davidson, and Harry D. Harootunian (University of Chicago Press, 1994), 282-289.

${ }_{15}$ R. Geuss, 'Genealogy as Critique,' European Journal of Philosophy 10, no. 2 (1 August 2002): 209-15.

${ }^{16}$ N. Carey, The Epigenetics Revolution: How Modern Biology is Rewriting Our Understanding of Genetics, Disease and Inheritance (London: Icon Books, 2012).

${ }^{17}$ S. Shapin, 'History of Science and Its Sociological Reconstructions,' History of Science, 21 July 2016.

${ }^{18}$ J. A. Caron, “Biology” in the Life Sciences: A Historiographical Contribution,' History of Science 26, no. 3 (September 1988): 223-68.
} 
This is a Pre-Print version of the following article:

Luca Chiapperino and Francesco Panese, 'On the Traces of the Biosocial: Historicizing "Plasticity" in Contemporary Epigenetics', History of Science, 18 November 2019, 42, https://doi.org/10.1177/0073275319876839.

19 C. $\underline{H}$._W Waddington, 'The Epigenotype', International Journal of Epidemiology 41 , no. 1 1_(1_February 2012): 10-13, https:_/_doi.org/10.1093/ĳe_Ldyr184. See also Meloni, Impressionable Biologies for a longer, pre-modern history of the plastic body in epigenetics.

${ }^{20}$ Ingold and Pálsson, Biosocial Becomings; Meloni et al., Biosocial Matters; Meloni et al, The Palgrave Handbook of Biology and Society.

${ }^{21}$ Ecological themes and environmental theories of health have dominated medical practices and views around the globe for several centuries. The history of plasticity thinking is certainly interwoven with that of views of the body and its alterations resulting from environmental changes. Several historians and sociologists have provided an analysis of these developments both in Western contexts and beyond. Addressing in full how notions of plasticity in the period we selected intertwine with different understandings of the body and the environment goes however beyond the scope of the present analysis. For an analysis of the longer history of plasticity in pre-modern times, see: Meloni, Impressionable Biologies. For an analysis of environmental theories of health beyond Western contexts, such as Arabic, Hindu and other ethno-medical regimes around the world. See: E. V. Daniel, Fluid Signs: Being a Person the Tamil Way (University of California Press, 1987); F. Zimmermann, 'The Jungle and the Aroma of Meats: An Ecological Theme in Hindu Medicine,' Social Science \& Medicine 27, no. 3 (1 January 1988): 197-206; W. Anderson, Colonial Pathologies: American Tropical Medicine, Race, and Hygiene in the Philippines (Duke University Press, 2006).

22 C. J. Glacken, Traces on the Rhodian Shore: Nature and Culture in Western Thought from Ancient Times to the End of the Eighteenth Century (University of California Press, 1967).

${ }_{23}$ Plato, Theaetetus, trans. Joe Sachs, (Newburyport, MA: Focus, 2004).

${ }^{24}$ C. Malabou, The Future of Hegel: Plasticity, Temporality, and Dialectic (New York: Routledge, 2005).

${ }^{25}$ Glacken, Traces on the Rhodian Shore.

${ }_{26}$ T. Rees, Plastic Reason: An Anthropology of Brain Science in Embryogenetic Terms (Oakland, California: University of California Press, 2016).

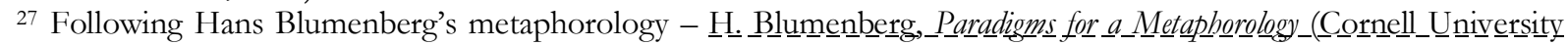
Press__2010) - 'plasticity' could be considered as (what the author calls) an "absolute metaphor"; namely, a heuristic "invested with a pragmatic function" that makes intelligible a great spectrum of phenomena whose empirical and conceptual foundations prove "resistant to terminological claims" (pp.4-5). In this view, plasticity thinking should not be regarded as a theoretical and/or empirical determination of bodies-environments entanglements that is confined to life sciences' reflections. Rather, plasticity as absolute metaphor is an intuitive/symbolic resource orienting reflections, practices and uses of bodies' porosity across different domains. Historically in fact, as argued by philosopher Catherine

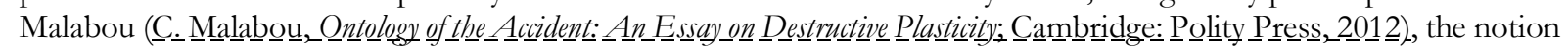
of plasticity has enabled different reflections around an ontology of becoming set in contrast to modern, static views of nature and the self. This ontology, Malabou shows, can be found in science, art, philosophy as well as educational sciences. Our paper sets out to analyze uses of plasticity that have enabled - and still enable - biological thinking about the openness of our bodies to their social and material environments. This notwithstanding, it is worth underlining that the scientific practices we describe here intersected with cultural practices grappling with plasticity beyond the life sciences. Specific examples of this crosstalk across science and socio-cultural practices could be found in the analysis of the historical cases we present.

${ }^{28}$ Caron, “'Biology” in the Life Sciences;' C. López-Beltrán, 'The Medical Origins of Heredity,' in S. Müller-Wille and H.-J. Rheinberger, Heredity Produced: At the Crossroads of Biology, Politics, and Culture, 1500-1870, (Cambridge, Mass: MIT Press, 2007), pp.105-32.

${ }^{29}$ S. Müller-Wille and C. Brandt, Heredity Explored: Between Public Domain and Experimental Science, 1850-1930 (MIT Press, 2016).

${ }^{30}$ Meloni, Impressionable Biologies.

31 M. Foucault, Society Must Be Defended: Lectures at the Collège de France, 1975-76, ed. Mauro Bertani et al., (New York: Picador, 2003), p.241.

32 I. Hacking, 'The Looping Effects of Human Kinds,' in Causal Cognition: A Multidisciplinary Debate, eds. D. Sperber, D. Premack, D., and A. James Premack (Oxford: Oxford University Press, 1996), pp.351-94. See also Foucault, Society Must Be Defended.

${ }_{3}^{3}$ Müller-Wille and Rheinberger, Heredity Produced; Müller-Wille and Brandt, Heredity Explored.

34 Meloni, Impression $\underline{\text { able }}$ _Biologies.

35 A comprehensive history of plasticity in the timeframe we selected would require to discuss other major milestones of its theorizations: from Charles Darwin's (1809-1882) theory of pangenesis, to Wilhelm Ludwig Johannsen's (18571927) distinction between genotype and phenotype, Richard Woltereck's (1877-1944) reaction norm, and Ivan Ivanovich Schmalhausen's (1884-1963) theorization of developmental plasticity within the framework of neoDarwininism (see Pigliucci, Phenotypic Plasticity and Nicoglu, 'The Evolution of Phenotypic Plasticity'). Yet, the historical instances we investigate enable us to draw a straightforward parallel with the epistemologies of plasticity in contemporary epigenetics. Yet, we do not mean to exclude that different past-to-present analogies may reveal other insights into contemporary epigenetics. For instance, a historico-epistemological analysis of how intergenerational 
This is a Pre-Print version of the following article:

Luca Chiapperino and Francesco Panese, 'On the Traces of the Biosocial: Historicizing "Plasticity" in Contemporary Epigenetics', History of Science, 18 November 2019, 42, https://doi.org/10.1177/0073275319876839.

transmission became a concern for biological knowledge-making about conception across the $19^{\text {th }}$ and $20^{\text {th }}$ centuries may reveal themes in current studies on epigenetic gestational programming that we do not explore here (see C. Arni, 'The Prenatal: Contingencies of Procreation and Transmission in the Nineteenth Century', in Müller-Wille and Brandt, Heredity Explored).

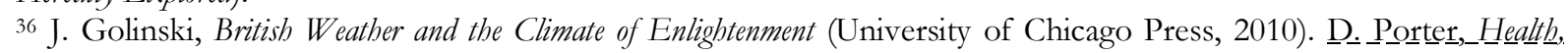

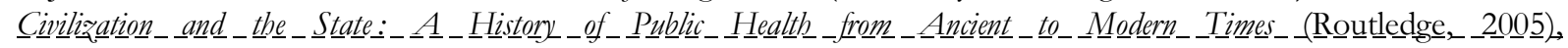

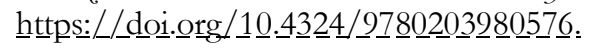

37 L. Loison, 'French Roots of French Neo-Lamarckisms, 1879-1985,' Journal of the History of Biology 44, no. 4 (1 November 2011): 713-44.

38 J.B. Lamarck, Philosophie Zoologique, Dentu (Paris, 1809), p.144.

${ }^{39}$ Before the French Revolution of 1848, public and private hygiene develops in France without any great relation to natural history. We note, however, that the project of a positive neo-Lamarckian biology - grounded on mechanical explanations of the deterministic relationship between organism and milieu - was formulated in the middle of 19th century in France as a complementary endeavor to hygienism; see L. Loison, Les Notions de Plasticité et d'hérédité Chez. Les Néolamarckiens Français (1879-1946): Éléments Pour Une Histoire Du Transformisme En France (Nantes, 2008).

${ }^{40}$ Cf. G. Jorland, Une société à soigner: Hygiène et salubrité publiques en France au XIXe siècle (Paris: Gallimard, 2010).

${ }^{41}$ In French, the word 'metabolism' was used for the first time in 1858 in the field of chemistry and was meant to cover the ensemble of internal molecular changes of the body instrumental to maintain life; see Oxford English Dictionary online, 'Metabolism, N.', (Oxford University Press, 2001), http://www.oed.com/view/Entry/117160.

${ }^{42}$ E. Tourtelle and J.-N. Hallé, Hygiène, Enyclopedie des sciences medicales (Paris, 1837), p.137; our translations henceforth; our emphasis.

43 A conception that very much resounds with the one purported in the 1850s by Claude Bernard (1813-1878): "Medicine possesses life modifiers. [...] All the science consists therefore of knowing how to handle these modifiers in a safe way, through the knowledge of the laws governing the body healthy, sick and modified by drug actions" (C. Bernard, Principes de Médecine Expérimentale (1858-1877), Université du Québec, Les Classiques Des Sciences Sociales (Chicoutimi, 2003), p.35). Yet, it is worth noting how experimental medicine in Bernard's view pertained to the action of these modifiers in the "internal milieu" (p.38) of the body.

44 Tourtelle and Hallé, Hygiène, p.xii.

${ }^{45}$ C. E. Perrin, 'Revolution or Reform: The Chemical Revolution and Eighteenth Century Concepts of Scientific Change,' History of Science, 21 July 2016.

46 For instance, equivalent approaches emphasizing bodily processes of self-healing can be found also in Germanspeaking contexts. See: J._Bleker, _Biedermeiermedizin _- Medizin _- Der _ Biedermeier

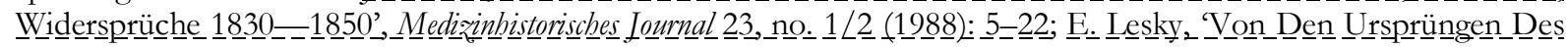

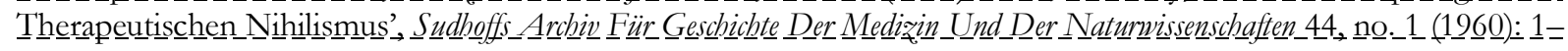
$\underline{2} \underline{0}$.

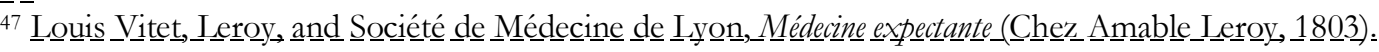

48 Jorland, Une société à soigner, p.13.

49 Models of policing population health have developed in the $18^{\text {th }}$ century on the basis of different epistemic and political conditions. For an overview on the rise of public health across different European contexts, see: G. Rosen,

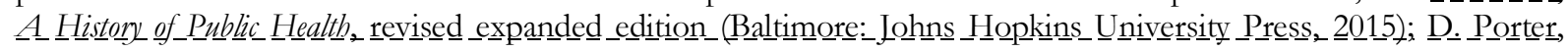

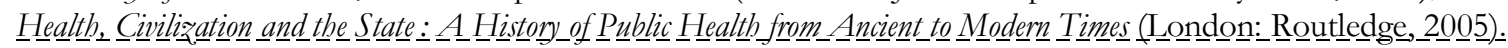

50 Tourtelle and Hallé, Hygiène, p.iv.

51 Müller-Wille and Brandt, Heredity Explored.

52 Müller-Wille and Brandt, Heredity Explored, p.13.

${ }^{53}$ Y. Delage, La Structure Du Protoplasme et Les Théories Sur l'hérédité et Les Grands Problèmes de La Biologie Générale (Paris: Reinwald \& C., 1895).

${ }^{54}$ Delage, La Structure Du Protoplasme, p.185.

55 Delage, La Structure Du Protoplasme, p.423.

56 Delage, La Structure Du Protoplasme, p.213-214.

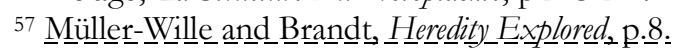

${ }^{58}$ E. Haeckel, Essais de Psychologie Cellulaire (Paris: Germer Billière et C., 1880), p.89.

59 E. P. Jacobsen, From Cosmology to Ecology: The Monist World-View in Germany from 1770 to 1930 (Peter Lang, 2005), p.106.

${ }^{60}$ Haeckel, Essais de Psychologie Cellulaire, p.87.

${ }^{61}$ Haeckel, Essais de Psychologie Cellulaire, p.77.

${ }^{62}$ Haeckel, Essais de Psychologie Cellulaire, p.80; emphasis added.

${ }^{63}$ A. Reynolds, 'Ernst Haeckel and the Theory of the Cell State: Remarks on the History of a Bio-Political Metaphor,' History of Science 46, no. 2 (June 2008): 123-52.

${ }^{64}$ Haeckel, Essais de Psychologie Cellulaire, p.131. 
This is a Pre-Print version of the following article:

Luca Chiapperino and Francesco Panese, 'On the Traces of the Biosocial: Historicizing "Plasticity" in Contemporary Epigenetics', History of Science, 18 November 2019, 42, https://doi.org/10.1177/0073275319876839.

${ }^{65}$ Haeckel, Essais de Psychologie Cellulaire, p.131; original emphasis.

${ }^{66}$ Haeckel, Essais de Psychologie Cellulaire, p.18.

${ }^{67}$ Haeckel, Essais de Psychologie Cellulaire, p.130.

${ }^{68}$ Haeckel, Essais de Psychologie Cellulaire, p.19. See also Reynolds 'Ernst Haeckel and the Theory of the Cell State.'

${ }^{69}$ We will not delve here into the limitations and allegations of fraud in Haeckel's work; see: N. Hopwood, Haeckel's Embryos: Images, Evolution, and Fraud (Chicago: University of Chicago Press, 2015).

${ }^{70}$ U. Hossfeld and L. Olsson, 'The Road from Haeckel: The Jena Tradition in Evolutionary Morphology and the Origins of "Evo-Devo", Biology and Philosophy 18, no. 2 (2003): 285-307.

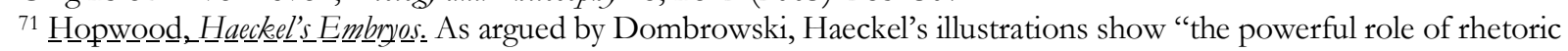
and ethics in scientific discourse in two ways." On the one hand, his drawings epitomize how science could be made relevant across "different branches of human thought and action." These images, the author shows, have influenced popular representations of development and evolution throughout the $20^{\text {th }}$ century. On the other hand, the accusations of fraud moved to these representations also show "the importance of ethos in technical and scientific discourse, and the damage that can follow from ethical lapses in visual communication". Haeckel's misrepresentations of embryological development have undermined not just his credibility, but also neo-Darwinian evolutionary thinking

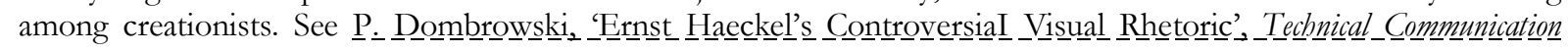
Quarterly 12,_no. 3 (1 July 2003): 303-19,-pp. $303-\underline{3} 04$.

72 The social ontology implicit in Haeckel's theory of organic memory has both constituted the basis for reactionary politics in fascist ideologies and inspired more progressive views of social development and eugenic policies at the beginning of the 20th century. See: D. Gasman, Haeckel's Monism and the Birth of Fascist Ideology, 2nd ed. edition (New York: Peter Lang Inc., International Academic Publishers, 1999); Logan, 'Engrams and Biological Regulation.' See also Meloni, Political Biology for an extensive analysis of progressive and reactionary interpretations of both Lamarckism and Mendelism.

73 A. Weismann, Essays upon Heredity and Kindred Biological Problems, trans. Edward Bagnall Poulton and Arthur Everett Shipley, vol. 1 (Clarendon press, 1889).

74 Weismann, Essays upon Heredity, p.165.

75 Weismann, Essays upon Heredity, p.191.

76 Weismann, Essays upon Heredity, p.165.

77 Weismann, Essays upon Heredity, p.104.

78 A. Weismann, The Germ-Plasm: A Theory of Heredity (W. Scott, limited, 1893).

${ }^{79}$ E. Jablonka and M. J. Lamb, Epigenetic Inheritance and Evolution: The Lamarckian Dimension (Oxford ; New York: Oxford University Press, 1995).

80 Weismann, Essays upon Heredity, pp.310 ff. See also R. G. Winther, 'August Weismann on Germ-Plasm Variation,' Journal of the History of Biology 34, no. 3 (2001): 517-55.

${ }^{81}$ Weismann, Essays upon Heredity, p.201.

82 Weismann, The Germ-Plasm.

83 Jablonka and Lamb, Epigenetic Inheritance and Evolution, p.37-43. See also Pigliucci, Phenotypic Plasticity; Nicoglou, 'The Evolution of Phenotypic Plasticity;' R. G. Winther, 'August Weismann on Germ-Plasm Variation,' Journal of the History of Biology 34, no. 3 (2001): 517-55.

${ }^{84}$ Winther, 'August Weismann on Germ-Plasm Variation,' p.550.

85 Weismann, Essays upon Heredity, p.201.

${ }^{86}$ G. B. Jacobi, 'Weismann and Lamarckism,' The Lancet, Originally published as Volume 1, Issue 4670, 181, no. 4670 (1 March 1913): 640-41, p.640.

${ }^{87}$ M. Meloni, 'The Transcendence of the Social: Durkheim, Weismann, and the Purification of Sociology,' Frontiers in Sociology 1 (22 July 2016), https://doi.org/10.3389/fsoc.2016.00011.

${ }^{88}$ T. . D. Lohns

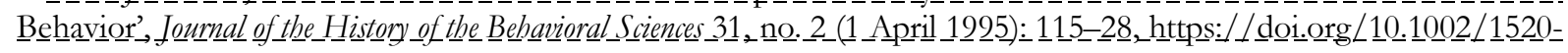

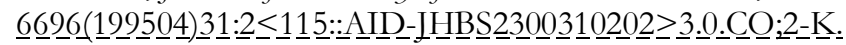

89 A. Dröscher, 'Images of_Cell Trees, Cell Lines, and_Cell_Fates: The Legacy of Ernst Haeckel and August Weismann

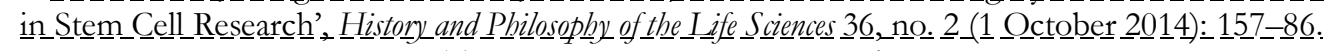

90 A. Dröscher, 'Images of Cell Trees, Cell Lines, and_Cell_Fatess'.

${ }^{91}$ Meloni, 'The Transcendence of the Social,' p.6.

${ }^{2}$ E. L. Peterson, The Life Organic: The Theoretical Biology Club and the Roots of Epigenetics, (Pittsburgh, Pa: University of Pittsburgh Press, 2017).

${ }^{3}$ Besides the Theoretical Biology Club that gathered scholars from Britain, continental Europe and the United States, this wave of thinkers includes also the affirmation of Lysenkoism as a mainstream position in Soviet Union science. See: E.L. Peterson, 'The Excluded Philosophy of Evo-Devo? Revisiting C.H. Waddington's Failed Attempt to Embed Alfred North Whitehead's “Organicism” in Evolutionary Biology,' History and Philosophy of the Life Sciences 33, no. 3 
This is a Pre-Print version of the following article:

Luca Chiapperino and Francesco Panese, 'On the Traces of the Biosocial: Historicizing "Plasticity" in Contemporary Epigenetics', History of Science, 18 November 2019, 42, https://doi.org/10.1177/0073275319876839.

(2011): 301-20; Peterson, The Life Organic, L. Graham, Lysenko's Ghost: Epigenetics and Russia (Cambridge, Massachusetts: Harvard University Press, 2016); Meloni, Political Biology.

94 C. H. Waddington, 'Genetic Assimilation of an Acquired Character,' Evolution 7, no. 2 (June 1953): 118; C. H. Waddington, The Strategy of the Genes (London New York: Routledge, 1957); C. H. Waddington, 'The Epigenotype,' International Journal of Epidemiology 41, no. 1 (1 February 2012): 10-13.

${ }^{25}$ Waddington, The Strategy of the Genes, p.29.

${ }^{96}$ P. Griffiths, 'The Distinction Between Innate and Acquired Characteristics,' in The Stanford Encyclopedia of Philosophy, ed. Edward N. Zalta, Spring 2017 (Metaphysics Research Lab, Stanford University, 2017), https://plato.stanford.edu/archives/spr2017/entries/innate-acquired/.

${ }_{97}$ Waddington, The Strategy of the Genes, p. 30-31.

${ }^{98}$ Waddington, 'Genetic Assimilation of an Acquired Character,' p.118.

${ }^{99}$ Waddington, The Strategy of the Genes, p. 167. See also Jablonka and Lamb, Epigenetic Inheritance and Evolution; L. Lo $\underline{\text { Lison, }}$ 'Canalization and _Genetic A Assimilation: Reassessing the Radicality of the W Waddingtonian Concept of Inheritance of Acquired_Characters', S Seminars in_Cell \& Developmental Biology 88_(April 2019):_4-13.

100 Peterson, 'The Excluded Philosophy of Evo-Devo?;' Peterson, The Life Organic.

101 Jablonka and Lamb, Epigenetic Inheritance and Evolution, p.32-34.

102 An extensive analysis of Waddington's legacy would require to distinguish between the early years and the Edinburgh years in his career, as well as between the influence of his ideas in genetics and related fields such as embryology. While, as we explain, his work was not highly regarded among geneticists for the concomitance of theoretical and political factors, his ideas were received differently in the pre- and post-war periods as well as beyond genetics. Through the years until the end of World War II his academic path was highly precarious to the point that the scepticism raised by his theories among neo-Darwinians also threatened the pursuit of his scientific career. The opportunity to join as director the Department of Genetics at the University of Edinburgh in 1947 constituted a turning point in Waddington's career. In Edinburgh, his work acquired a more solid institutional and scientific anchoring. His Epigenetics Laboratory was, as argued by Brian K. Hall, the "largest and perhaps the strongest Genetics

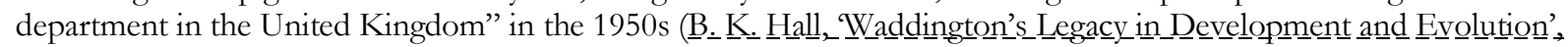
American_Zoologist 32, no. 1 _(February_1992):_113_22,_p.115). This notwithstanding, Hall and others (e.g. Loison, 'Canalization and Genetic____ssimilation')_also_remind us that the mood of the biological world of the time was not ready for the developmental and integrative ideas developed in Waddington's lab. Coupled with the unfolding of the Lysenko affair, the reductionist and molecular thinking of the Synthesis foreclosed a full uptake of Waddington's ideas in genetics circles (see: Peterson, The Life Organic, ch. 8-11). Things stand differently if we look at the impact of Waddington's work in related biological fields, such as embryology. Due to the conceptual and epistemological differences that emerged in the 1930s between genetics and embryology, Waddington's work found greater recognition

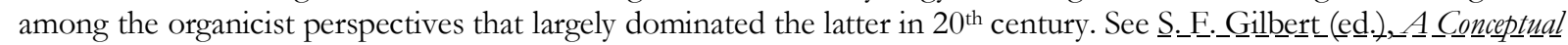

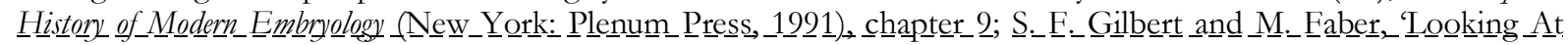
Embrogos: The Visual_And Conceptual Aes A.I. Tauber, (Dordrecht: Kluwer Academic Publishers, 1996), 125-51.; R. M. Burian and D. Thieffry, 'Introduction to

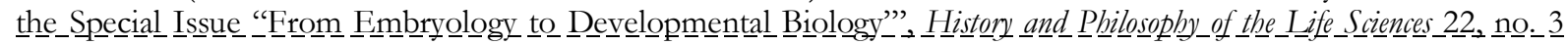
(2000): $\underline{3} \underline{1} \underline{3}-2 \underline{3}$.

103 Pigliucci, Phenotypic Plasticity, p.53. As shown by Peterson, plasticity thinking was indeed isolated during the years following the Modern Synthesis, but nevertheless never disappeared (see Peterson, The Life Organic, ch.12). See Pigliucci, Phenotypic Plasticity, ch.3 for an analysis of the continuity of plasticity thinking after the period we analyze.

104 Peterson, 'The Excluded Philosophy of Evo-Devo?.'

105 C. H. Waddington, The Scientific Attitude, 1 edition (Routledge, 1948).

106 Graham, Lysenko's Ghost.

107 Waddington, The Strategy of the Genes, p.189.

108 Peterson, The Life Organic.

109 Waddington, The Scientific Attitude.

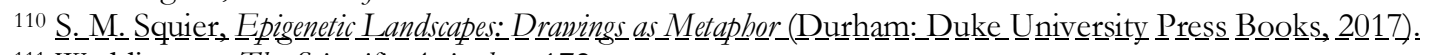

111 Waddington, The Scientific Attitude, p.172.

112 Although Waddington's production provides several instances of such programmatic ambition to develop a organicist unified theory of social, cultural and biological phenomena, Susan Merril Squier nicely shows how this objective was not accomplished for several reasons and how this failure still narrows the program of contemporary epigenetics. Waddington, she argues, was unable to resist the "canalization" of epigenetics by disciplinary forces that turned his holistic, extensive and visual grasp of biology into a statistically-based, analytical and quantitative

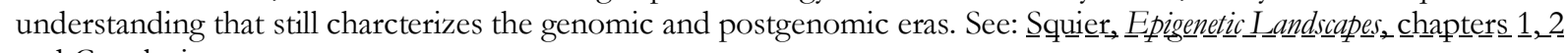
and $\underline{\text { Conclusions. }}$ ‥

113 Waddington, The Scientific Attitude, p.172. See also: I._M.

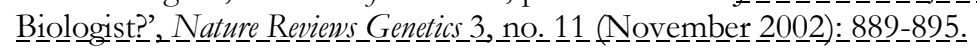


This is a Pre-Print version of the following article:

Luca Chiapperino and Francesco Panese, 'On the Traces of the Biosocial: Historicizing "Plasticity" in Contemporary Epigenetics', History of Science, 18 November 2019, 42, https://doi.org/10.1177/0073275319876839.

114 Buklijas, 'Histories and Meanings of Epigenetics'.

115 D. Haig, 'The (Dual) Origin of Epigenetics,' Cold Spring Harbor Symposia on Quantitative Biology 69 (1 January 2004): 67-70; R. Holliday, 'Epigenetics: A Historical Overview,' Epigenetics 1, no. 2 (2006): 76-80

116 M. Morange, 'The Relations between Genetics and Epigenetics,' Annals of the New York. Academy of Sciences 981, no. 1 (1 December 2002): 50-60.

${ }^{117}$ Roadmap Epigenomics Consortium et al., 'Integrative Analysis of 111 Reference Human Epigenomes,' Nature 518, no. 7539 (19 February 2015): 317-30.

118 Y. Atlasi and H. G. Stunnenberg, 'The Interplay of Epigenetic Marks during Stem Cell Differentiation and Development,' Nature Reviews Genetics 18, no. 11 (14 August 2017): 643-58, p.645.

119 Indeed, it is not rare for epigenomic scientists to frame themselves as being in full continuity with Waddington's work, see: R. Jaenisch and A. Bird, 'Epigenetic Regulation of Gene Expression: How the Genome Integrates Intrinsic and Environmental Signals,' Nature Genetics 33 (1 March 2003): 245-54. Interestingly, newly emerging epigenomeediting possibilities have been welcomed as a technoscientific opportunity to innovate on his legacy. This opportunity has been represented as rendering the conformation of Waddington's landscape a dynamic, ever-changing surface. A movie rendition of this new version of Waddington's model can be found in the online supplementary materials of S. H. Stricker, A. Köferle, and S. Beck, 'From Profiles to Function in Epigenomics,' Nature Reviews Genetics 18 , no. 1 (21 November 2016): 51-66.

${ }^{120}$ F. Crick, 'Central Dogma of Molecular Biology,' Nature 227, no. 5258 (8 August 1970): 561-63.

${ }^{121}$ L. Moss, 'One, Two (Too?), Many Genes? A Review of "The Concept Of The Gene In Development And Evolution: Historical And Epistemological Perspectives," in Cambridge Studies in Philosophy and Biology, edited by P. J. Beurton, R. Falk, and H.-J. Rheinberger. Cambridge and New York: Cambridge University Press (March 2003): pp.5767.

122 E. F. Keller, The Mirage of a Space between Nature and Nurture (Durham, NC: Duke University Press, 2010).

123 J. R. Dixon et al., 'Chromatin Architecture Reorganization during Stem Cell Differentiation,' Nature 518, no. 7539 (18 February 2015): 331-36.

124 E. Gjoneska et al., 'Conserved Epigenomic Signals in Mice and Humans Reveal Immune Basis of Alzheimer's Disease,' Nature 518, no. 7539 (18 February 2015): 365-69.

125 T. M. Powledge, 'Behavioral Epigenetics: How Nurture Shapes Nature,' BioScience 61, no. 8 (1 August 2011): 58892, p.588.

${ }^{126}$ M. K. Skinner, 'Endocrine Disruptors and Epigenetic Transgenerational Disease Etiology,' Pediatric Research 61, no. 5 Part 2 (May 2007): 48R-50R.

${ }^{127}$ K. Gapp et al., 'Early Life Epigenetic Programming and Transmission of Stress-Induced Traits in Mammals,' BioEssays 36, no. 5 (1 May 2014): 491-502.

${ }_{128}$ M. Szyf, 'Nongenetic Inheritance and Transgenerational Epigenetics,' Trends in Molecular Medicine 21, no. 2 (2 January 2015): $134-44$.

${ }^{129}$ Szyf, 'Nongenetic Inheritance and Transgenerational Epigenetics,' p.138. Emphasis added.

130 Epigenetic variations as neo-Lamarckian mechanisms of evolution in the received neo-Darwinian theory of evolution are a long-standing matter of controversy in theoretical biology and evolutionary thinking, which far exceeds the contributions we discuss here (see Jablonka and Lamb, Epigenetic Inheritance and Evolution). We have privileged however to illustrate this issue as approached by Szyf and Skinner as their research programs enable a description of how actors in contemporary epigenetics operationalize and conceptualize plasticity - as a notion straddling ontogeny and phylogeny - within their experimental practices. See also: Moshe Szyf, 'Lamarck Revisited: Epigenetic Inheritance of Ancestral Odor Fear Conditioning,' Nature Neuroscience 17, no. 1 (January 2014): 2-4.

131 Szyf, 'Lamarck Revisited.'

132 The support of mechanisms of neo-Lamarckian inheritance from studies of transgenerational epigenetic inheritance in mammals has been challenged by several authors. See for an overview: Whitelaw, 'Disputing Lamarckian Epigenetic Inheritance in Mammals.'

133 Szyf, 'Lamarck Revisited,' p.3.

134 Szyf, 'Lamarck Revisited,' p.4.

135 Skinner, 'Environmental Epigenetics and a Unified Theory of the Molecular Aspects of Evolution,' p. 1299.

136 A systematic Web of Knowledge search through all the publications of authors "Skinner, Michael K." and "Szyf, Moshe" yielded no results when queried for terms such as: "organic memory", "Ernst Haeckel", "Haeckel", "plastidule".

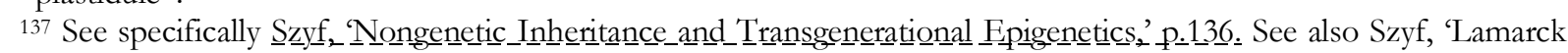
Revisited,' and Skinner, 'Environmental Epigenetics and a Unified Theory of the Molecular Aspects of Evolution.'

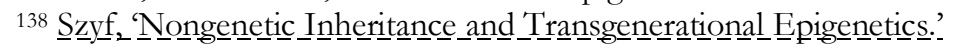

139 M. Szyf, 'Behavior and Epigenetics: Long-Term Plasticity of the Epigenome?,' Journal of Perinatal Medicine 38, no. s1 (2010); Z. Hochberg et al., 'Child Health, Developmental Plasticity, and Epigenetic Programming,' Endocrine Reviews 32, no. 2 (April 2011): 159-224. 
This is a Pre-Print version of the following article:

Luca Chiapperino and Francesco Panese, 'On the Traces of the Biosocial: Historicizing "Plasticity" in Contemporary Epigenetics', History of Science, 18 November 2019, 42, https://doi.org/10.1177/0073275319876839.

140 Skinner, 'Environmental Epigenetics and a Unified Theory of the Molecular Aspects of Evolution.'

141 Szyf, 'Lamarck Revisited,' p.3.

142 Müller-Wille and Rheinberger, Heredity Produced.

${ }^{143}$ K. B. Michels, ed., Epigenetic Epidemiology (Dordrecht: Springer Netherlands, 2012), p.1.

${ }^{144}$ D. McGuinness et al., 'Socio-Economic Status Is Associated with Epigenetic Differences in the PSoBid Cohort,' International Journal of Epidemiology 41, no. 1 (1 February 2012): 151-60.

145 R. A. Waterland and K. B. Michels, 'Epigenetic Epidemiology of the Developmental Origins Hypothesis,' Annual Review of Nutrition 27, no. 1 (2007): 363-88.

146 A. M. Vaiserman, V. P. Voitenko, and L. V. Mekhova, 'Epigenetic Epidemiology of Age-Related Diseases,' Russian Journal of Developmental Biology 42, no. 1 (January 2011): 25-42, p.27.

${ }_{147}$ C. P. Wild, 'Complementing the Genome with an "Exposome": The Outstanding Challenge of Environmental Exposure Measurement in Molecular Epidemiology,' Cancer Epidemiology and Prevention Biomarkers 14, no. 8 (1 August 2005): 1847-50; S. M. Rappaport and M. T. Smith, 'Environment and Disease Risks,' Science 330, no. 6003 (22 October 2010): 460-61; C. P. Wild, 'The Exposome: From Concept to Utility,' International Journal of Epidemiology 41, no. 1 (1 February 2012): 24-32.

${ }^{148}$ K. Olden et al., 'Epigenome: Biosensor of Cumulative Exposure to Chemical and Nonchemical Stressors Related to Environmental Justice,' American Journal of Public Health 104, no. 10 (October 2014): 1816-21, p.1817.

${ }^{149}$ S. M. Rappaport et al., 'The Blood Exposome and Its Role in Discovering Causes of Disease,' Environmental Health Perspectives 122, no. 8 (August 2014): 769-74.

150 Wild, 'Complementing the Genome with an "Exposome.",

151 Rappaport et al., 'The Blood Exposome.'

152 Rappaport and Smith, 'Environment and Disease Risks,' p.461.

153 Rappaport et al. 'The Blood Exposome,' p.769.

154 Rappaport et al. 'The Blood Exposome.'

155 Wild, 'Complementing the Genome with an "Exposome."'

${ }^{156}$ H. Landecker and A. Panofsky, "From Social Structure to Gene Regulation, and Back: A Critical Introduction to Environmental Epigenetics for Sociology,' Annual Review of Sociology 39, no. 1 (30 July 2013): 333-57, p.341.

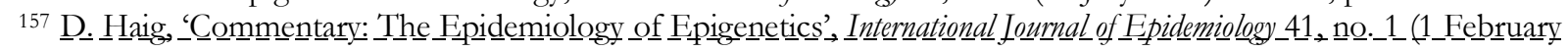

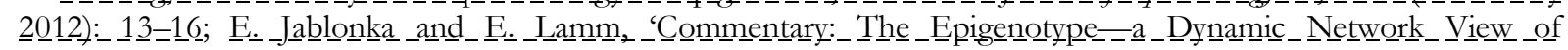
Development', International Journal of Expidemiology_41 no.11_(1_February 2012):16-20; S. F._Gilbert, 'Commentary: “The

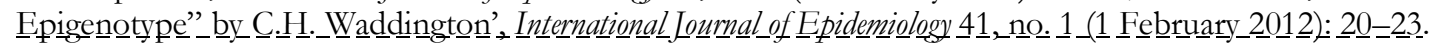

158 McGuinness et al., _Socio-Economic Status Is Associated_with Epigenetic_Differences in the PSoBid Cohort'; $\underline{\text { S }}$. Ebrahim, 'Epigenetics: The next_Big Thing',_International Journal of Epidemiology 41,_no. 1_(1 February 2012):_1-3; C.L.

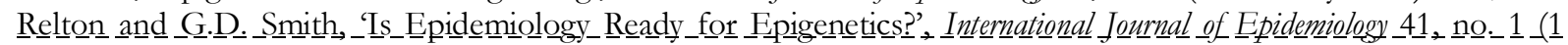
February_2012): $\underline{5}_{-}$. . The whole journal issue can be consulted at the url: https://academic.oup.com/ije/issue/41/1 (last access: 17/04/2019).

159 Wild, 'The Exposome

160 'Plasticity, Robustness, Development and Evolution', International Lournal of Eptidemiology 41, no. 1 (1 February 2012): 218-21; ; P. Bateson and_P.D. _Gluckman,_Plasticity, Robustness, _Development_and_Evolution _Cambridge: Cambridge University Press 2 2011).

${ }^{161}$ C.. H. Waddington, 'The Epigenotype', p. 10 .

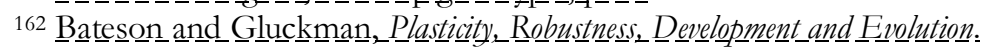

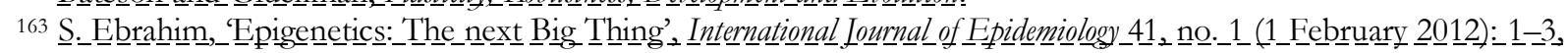
p.1. References to the role of the environment for the epigenotype in Waddington's work can be found elsewhere: e.g. C.H. Waddington, An Introduction to Modern genetics (New York: Macmillan, 1939), p.156; Waddington, The Strategy of the Genes, ch. 2 .

$164 \mathrm{~A}$ full reconstruction of how the hygienist tradition survived throughout the last two centuries exceeds the scope of our paper. Nonetheless, it is worth reminding here how hygienism has inspired a longstanding tradition of scientific and political concerns with the effects of the material and social milieu over health. As argued by philosopher Ferhat Taylan, the $19^{\text {th }}$ century has been characterized by the establishment of a "mesopolitics" - a set of knowledge and intervention strategies acting on the material and social environment to prevent illness - that still permeates ecological

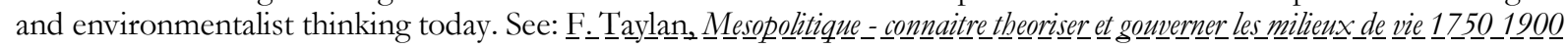
(Paris: Editions Sorbonne, 2018). For an analysis of the governmentalities stemming from $19^{\text {th }}$ century social medicine across the French, German and English contexts, see M. Foucault, Power: Essential W_orks of Foucault, 1954-1984, ed. J.

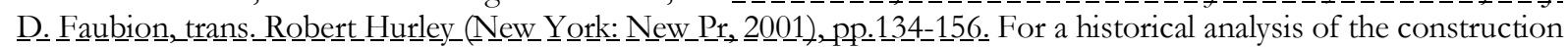
of public health systems across different modern and contemporary political systems, see:_Rosen_.

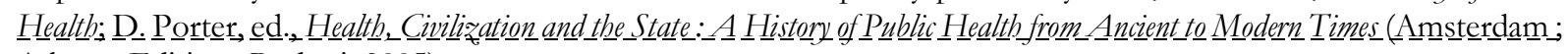

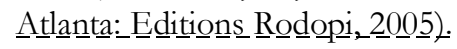


This is a Pre-Print version of the following article:

Luca Chiapperino and Francesco Panese, 'On the Traces of the Biosocial: Historicizing "Plasticity" in Contemporary Epigenetics', History of Science, 18 November 2019, 42, https://doi.org/10.1177/0073275319876839.

165 Müller-Wille and Rheinberger, Heredity Produced; J. Maienschein, 'Epigenesis and Preformationism,' in The Stanford Encyclopedia of Philosophy, ed. Edward N. Zalta, Spring 2017 (Metaphysics Research Lab, Stanford University, 2017), https://plato.stanford.edu/archives/spr2017/entries/epigenesis/.

166 Meloni et al., eds., The Palgrave Handbook of Biology and Society.

${ }^{167}$ C. L. Relton and G. D. Smith, 'Is Epidemiology Ready for Epigenetics?,' International Journal of Epidemiology 41, no. 1 (1 February 2012): 5-9; Stricker, Köferle, and Beck, 'From Profiles to Function in Epigenomics;' M. K. Skinner, 'Environmental Epigenetics and a Unified Theory of the Molecular Aspects of Evolution.'

${ }^{168}$ H. Landecker, 'The Social as Signal in the Body of Chromatin,' The Sociological Review Monographs 64, no. 1 (1 March 2016): 79-99.

169 Cf. Malabou, The Future of Hegel.

${ }_{170}$ M. D. Anway et al., 'Epigenetic Transgenerational Actions of Endocrine Disruptors and Male Fertility,' Science (New York, N.Y.) 308, no. 5727 (3 June 2005): 1466-69.

${ }^{171}$ Landecker and Panofsky, 'From Social Structure to Gene Regulation, and Back,' p.341.

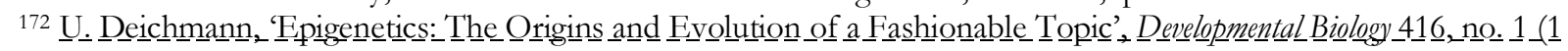
August 2016): 249-54. See also U. Deichmann, _Why Epigenetics_Is Not_a Vindication of Lamarckism =_and_Why

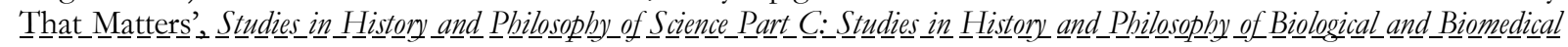
Science $\underline{5}$ 그 (1_June 2016): 0 80-82.

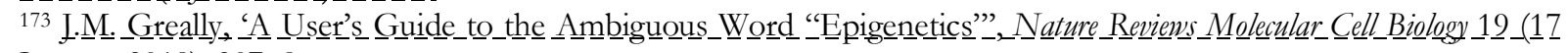

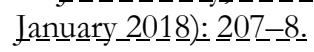

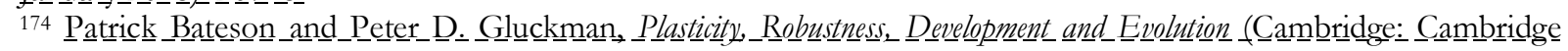
University Press 2 2011).

175 Adrian _ B Bird, _

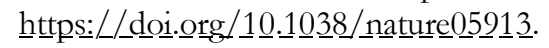

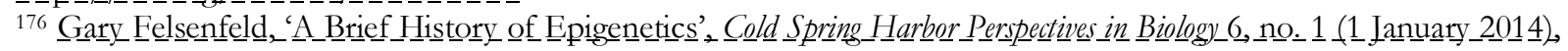
https:_/_doi.org/10.11이/_shperspect.a018200.

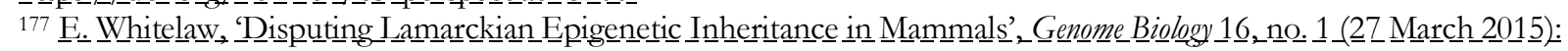

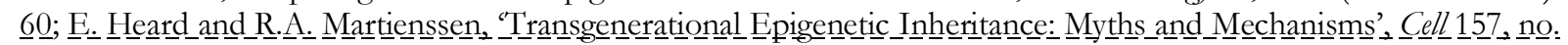

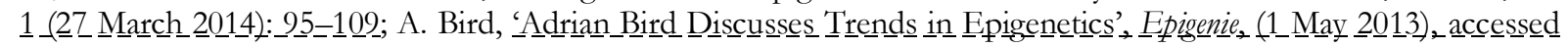
23 April 2019, https:L/epigenie.com/dissolving-the-layers-in-genetics-and-epigenetic - 2 -

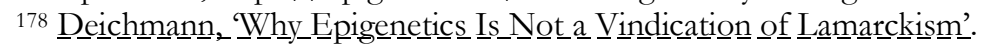

179 Meloni, Impressionable Biologies; Buklijas, 'Histories and Meanings of Epigenetics.'

${ }^{180}$ Nicolosi and Ruivenkamp, 'The Epigenetic Turn'; Carey, The Epigenetics Revolution.

181 Carey, The Epigenetics Revolution.

182 Even the so-called model of gene-centrism could be seen more as a historical approximation than a homogeneous paradigm dominating biological thinking in the second half of 20th century. As shown by Rheinberger and colleagues, the focus on 'the gene' did not resolve fundamental controversies related to plasticity at the core of biology. Rather, the success of this model lied primarily at an epistemological and pragmatic level, and not at an ontological one. Thus, the authors remind us that the explanatory system of the gene was never considered complete, nor devoid of any criticism. See: H.-J. Rheinberger, S. Müller-Wille, and R. Meunier, 'Gene,' in The Stanford Encyclopedia of Philosophy, ed. Edward N. Zalta, Spring 2015 (Metaphysics Research Lab, Stanford University, 2015), https://plato.stanford.edu/archives/spr2015/entries/gene/. See also: Pigliucci, Phenotypic Plasticity; Fox Keller, The Mirage of a Space between Nature and Nurture; Peterson, The Life Organic.

${ }^{183}$ Ingold and Pálsson, Biosocial Becomings; Meloni et al. Biosocial Matters; Meloni et al. The Handbook of Biology and Society; Meloni, Impressionable Biologies.

184 Jorland, Une société à soigner.

185 P. Rabinow, Essays on the Anthropology of Reason, Princeton Studies in Culture/Power/History (Princeton, N.J: Princeton University Press, 1996).

186 Ingold and Pálsson, Biosocial Becomings.

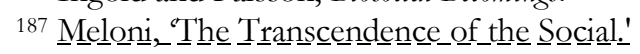

188 Niewöhner, 'Epigenetics.'

189 B. Latour, 'Why Has Critique Run out of Steam? From Matters of Fact to Matters of Concern,' Critical Inquiry 30, no. 2 (2004): 225-248, p.227.

${ }^{190}$ Ingold and Pálsson, Biosocial Becomings; Meloni et al. Biosocial Matters; Meloni et al. The Handbook of Biology and Society; Meloni, Impressionable Biologies.

191 I._Niewöhner and M._L_Lock, ‘Situating_Local Biologies: Anthropological Perspectives on_Environment/_Human Entanglementss, Bio So 0 cieties 2 5 April 2018, $1=17$.

192 Peterson, The Life Organic.

193 Meloni, Political Biology.

194 Shapin, 'History of Science and Its Sociological Reconstructions.' 
This is a Pre-Print version of the following article:

Luca Chiapperino and Francesco Panese, 'On the Traces of the Biosocial: Historicizing "Plasticity" in Contemporary Epigenetics', History of Science, 18 November 2019, 42, https://doi.org/10.1177/0073275319876839.

195 See also Meloni, Impressionable Biologies, p.18. 